\title{
The diagnostic accuracy of RT-PCR from self-collected saliva versus nasopharyngeal sampling
}

\author{
A systematic review and meta-analysis
}

Do Hyun Kim, MD, PhD, Mohammed A. Basurrah, MD, Jae Hong Han, MD, Sung Won Kim, MD, PhD, Se Hwan Hwang, MD, PhD.

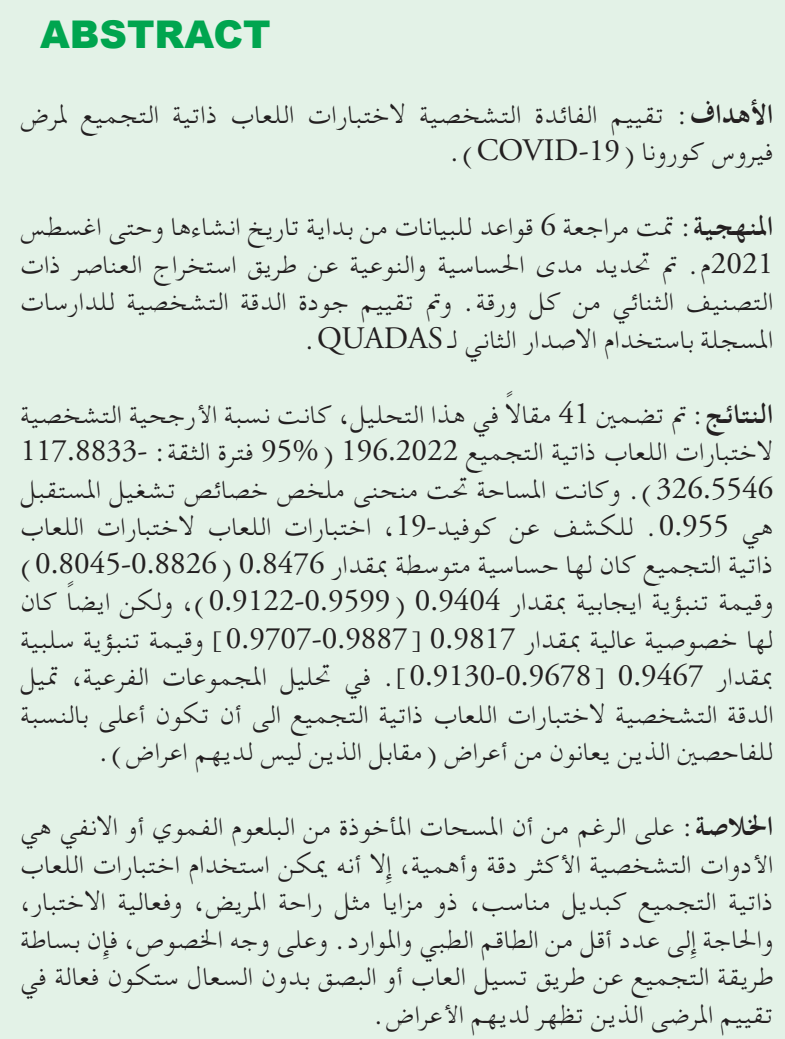

Objectives: To evaluate the diagnostic utility of selfcollected saliva in coronavirus desease-19 (COVID-19) screening procedures.

Methods: A total of 6 databases were reviewed from their inception until August 2021. Sensitivity and specificity were measured by extracting items (true-positive, truenegative, false-positive and false-negative) from each paper. We evaluated the diagnostic accuracy based on Quality Assessment of Diagnostic Accuracy Studies, version 2.

Results: A total of 41 studies were included in the final analysis. The diagnostic odds ratio (OR) of self-collected saliva was 196.2022 (95\% confidence interval [CI]:
117.8833-326.5546). The area under the summary receiver operating characteristic curve was 0.955 . For detecting COVID-19, self-collected saliva had a moderate sensitivity of $0.8476[0.8045-0.8826]$ and positive predictive value of 0.9404 [0.9122-0.9599] but high specificity of 0.9817 [0.9707-0.9887] and negative predictive value of 0.9467 [0.9130-0.9678]. In a subgroup analysis, the diagnostic accuracy of selfcollected saliva tended to be higher for symptomatic (vs. asymptomatic) examinees.

Conclusion: Although naso/oropharyngeal swab tests are the most accurate and important diagnostic tools, the saliva-based testing method can be used as a suitable alternative test, with the advantages of increased patient convenience, efficient testing, and the need for fewer medical staff and resources. In particular, simple collecting method such as drooling or spitting without coughing would be effective in evaluating the symptomatic patients.

PROSPERO no.: CRD42021279287

Keywords: coronavirus infections, nasopharynx, saliva, specimen handling

Saudi Med J 2022; Vol. 43 (1): 9-30

doi: 10.15537/smj.2022.43.1.20210743

From the Department of Otolaryngology-Head and Neck Surgery (DH. Kim, Han, SW. Kim), Seoul Saint Mary's Hospital; from the Department of Otolaryngology-Head and Neck Surgery (Hwang), Bucheon Saint Mary's Hospital, College of Medicine, The Catholic University of Korea, Seoul, Korea, and from the Department of Surgery (Basurrah), College of Medicine, Taif University, Taif, Kingdom of Saudi Arabia.

Received 21st September 2021. Accepted 7th December 2021.

Address correspondence and reprint request to: Dr. Se Hwan Hwang, Department of Otolaryngology-Head and Neck Surgery, Bucheon Saint Mary's Hospital, College of Medicine, The Catholic University of Korea, Seoul, Korea.E-mail:yellobird@catholic.ac.kr ORCID ID: https://orcid.org/0000-0002-2838-7820 
Since first detected in 2019, the severe acute $\checkmark$ respiratory syndrome coronavirus-2 (SARS-CoV-2) pandemic is still ongoing. This newly discovered coronavirus has a high ability to be transmitted from person to person through respiratory aerosols, droplets, or vomitus. ${ }^{1}$ More than $80 \%$ of patients infected by coronavirus disease-19 (COVID-19) show symptoms similar to influenza infection or pneumonia. Therefore, most patients do not require hospitalization. ${ }^{2}$ Because of these features of COVID-19, significant viral transmission from mildly symptomatic and non-hospitalized patients is concerning. ${ }^{3}$ However, COVID-19 can cause severe morbidity or mortality in the elderly, immunocompromised patients, and those with comorbidities such as heart disease, obesity, and diabetes. $^{4}$

Although there are a few known treatments for COVID-19, strict isolation of confirmed patients based on accurate diagnosis of COVID-19 is the key to overcome the pandemic, given the circumstances that only few treatment methods are available. ${ }^{5}$ Generally, the definitive diagnostic test of COVID-19 relies mostly on detection via reverse transcription quantitative polymerase chain reaction (RT-qPCR) carried out in respiratory samples. ${ }^{6}$ However, the collection of naso/oropharyngeal swab samples can cause nasal pain to the examinees, and health care personnel performing the test should be equipped with individual protective equipment to protect them against the risk of virus exposure. ${ }^{7}$ Testing using self-collected saliva methods have been reported to have several advantages of convenience and safety compared with the naso/oropharyngeal swab method because it eliminates close contact when obtaining a sample and the necessity of personal protective equipment. In addition, saliva collection is painless and thus, minimizes inconvenience for the examinees. ${ }^{8}$ Recently, published studies have reported that saliva specimens could be an alternative to naso/oropharyngeal specimens, but the evidence is still limited..$^{9}$ It is important to clarify the diagnostic power of saliva for COVID-19 to improve the convenience to examinees and inspectors when mass rapid examination is required. Therefore, the aim of this study was to define the diagnostic accuracy of RT-qPCR from saliva compared to naso/oropharyngeal swab results.

Methods. This meta-analyses and systematic reviews used terms such as COVID-19, coronavirus,

Disclosure. Authors have no conflict of interests, and the work was not supported or funded by any drug company. coronavirus disease-19, severe acute respiratory syndrome coronavirus-2, saliva, nasopharyngeal swab, oropharyngeal swab, PCR, and diagnostic accuracy as keywords. Database from PubMed, the Cochrane Central Register of Controlled Trials, Embase, Web of Science, SCOPUS, and Google Scholar were searched. Only papers written in English were reviewed. All references of the included articles were assessed to confirm that no significant studies were neglected. Two reviewers independently reviewed candidate studies, conducted title, abstract, full-text reviews, and inclusion of the final agreed papers.

The present study includes: i) prospective or retrospective study protocol; from ii) cases of COVID-19 suspected symptoms or asymptomatic population screening, using iii) index test: RT-qPCR in self-collected saliva specimens to detect SARS-CoV-2, with iv) reference standard (comparator test) of RT-qPCR in naso/oropharyngeal specimens to detect SARS-CoV-2, and v) qualified articles for sensitivity and specificity analysis (Appendix 1). We excluded reviews, case reports, and studies with low diagnostic power in saliva specimens. The search flow diagram was presented in Figure 1.

We calculated the area under the curve (AUC) of summary receiver operating characteristic (SROC) curve designed from diagnostic accuracy (namely, diagnostic odds ratio [DOR]). ${ }^{7,8,10-48}$

Diagnostic odds ratio was defined as true positive $\mathrm{x}$ true negative / false positive $\mathrm{x}$ false negative, within 95\% confidence interval (CI) from a random effect model with intra- and inter-study variations. The higher the value of DOR, the better the performance of the diagnostic method. Diagnostic odds ratio of one means it is not assured whether the disease is present. We calculated the log of DOR to examine an approximate

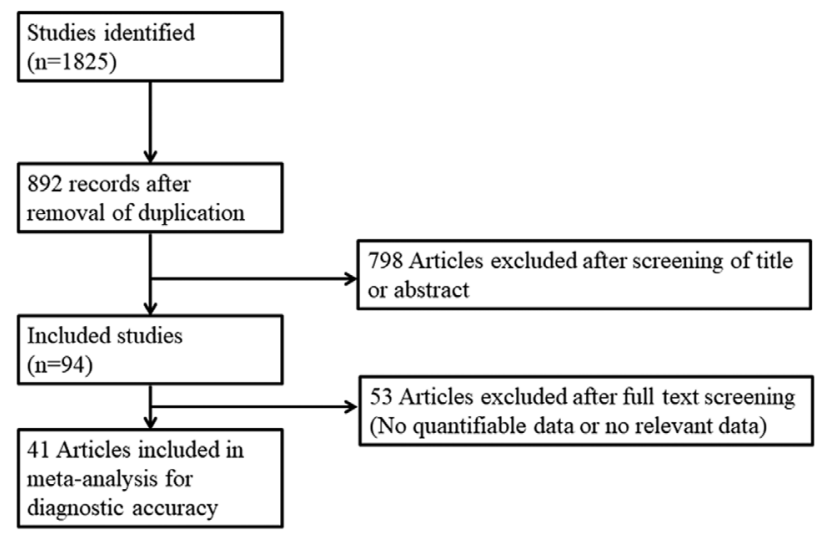

Figure 1 - Summary of the search strategy. 
normal distribution. ${ }^{49}$ The SROC method derives both sensitivity and specificity through meta-analysis. The SROC curve moves towards the left upper quadrant (namely, sensitivity and specificity to $1[100 \%]$ ) as the discriminative force increases. Area under the curve ranges from 0-1 with higher value indicating superior performance. We estimated and compared the accordance of RT-qPCR results between the saliva and naso/oropharyngeal swab samples using Cohen's kappa coefficient ( $\kappa)$. Data of true-positive, true-negative, false-positive, and false-negative values used to calculate the AUC and DOR were collected. The qualitative agreement across sample types (naso/oropharyngeal swab and saliva specimen) was assessed.

Quality examination was carried out by Quality Assessment of Diagnostic Accuracy Studies tool, version 2.

Statistical analysis. We used the version 3.6.1 of $\mathrm{R}$ software for statistical analysis ( $\mathrm{R}$ Foundation for Statistical Computing, Vienna, Austria) and Q statistics for homogeneity analysis. Citation management was conducted by EndNote version 20.1 (Clarivate Analytics, PA, USA). Summary receiver operating characteristic curves were drawn from forest plots of sensitivity, specificity, negative predictive value (NPV), and positive predictive value. Coefficients were converted to Fisher's exact values for normal distribution and variance stabilization between different sample types. After completing the meta-analysis, Fisher's exact values were converted back to the intra-class correlation coefficient to aid in the interpretation of the results. ${ }^{50}$

Results. The present meta-analysis included 41 studies of 14,011 patients. Appendix 2 summarizes the participant characteristics and Appendix 3 shows the quality analysis of methods.

A total of 41 observational studies that used selfcollected saliva samples for COVID-19 diagnosis were included in this study. The DOR of self-collected saliva for COVID-19 was 196.2022 (95\% CI: [117.8833-326.5546], $\mathrm{I}^{2}=82 \%$; Figure 2) and the AUC was 0.955 (Figure 3). The self-collected saliva samples had a moderate sensitivity of 0.8476 (95\% CI: [0.8045-0.8826], $\left.\mathrm{I}^{2}=87.3 \%\right)$ and PPV of $0.9404(95 \%$ CI: $\left.[0.9122-0.9599], \mathrm{I}^{2}=83.2 \%\right)$ but a high specificity of 0.9817 (95\% CI: [0.9707-0.9887], $\left.\mathrm{I}^{2}=89 \%\right)$ and NPV of 0.9467 (95\% CI: [0.9130-0.9678], I²=96.4\%; Appendix 4-7).

In concern of the heterogeneity of diagnostic accuracy, we looked for significant bias among the included studies. Subgroups were analyzed to assess the influence of geographic differences, saliva collection method, and presence or absence of symptoms (Table 1). Through these analyses, it was confirmed that there was no significant difference between continents.

For the saliva collection method, there were 3 subgroups: enhanced saliva (including posterior pharyngeal saliva or induced cough), oral saliva only without cough, and oral saliva only not defined regarding cough. Diagnostic accuracy tended to be lower in the enhanced saliva than the other 2 subgroups (sensitivity: 0.8353 vs. 0.8365 and 0.8919 , specificity: 0.9779 vs. 0.9827 and 0.9820 , and NPV: 0.8823 vs. 0.9496 and 0.9731; Appendix 8-10, DOR: 127.2254 vs. 215.1566 and 237.4246 except PPV: 0.9654 vs. 0.9202 and 0.8510; Appendix 11-13). Regarding the presence/absence of symptoms in patients during testing, diagnostic accuracy tended to be higher in the symptomatic than non-symptomatic patients (sensitivity: 0.8851 vs. 0.8208 and 0.7049 , specificity: 0.9791 vs. 0.9783 and 0.9933 , NPV: 0.9522 vs. 0.9164 and 0.9772 , PPV: 0.9495 vs. 0.9435 and 0.8483, DOR: 245.6222 vs. 159.4638 and 184.8991). All analyses performed on each subgroup showed high heterogeneity. Based on this, it is difficult to document that subgroup analysis explains heterogeneity.

A total of 16 studies reported the Cohen's kappa coefficient; the summary intra-class correlation coefficient was 0.8506 (95\% CI: [0.8024-0.8877]), and the heterogeneity was high $\left(\mathrm{I}^{2}=97.05 \%\right)$. Therefore, the correlation coefficients represented a good qualitative agreement between the standard naso/oropharyngeal swab and saliva samples in this meta-analysis.

Discussion. Because of the rapid global spread of COVID-19 and its high morbidity and mortality rates at older ages, early and accurate diagnosis of COVID-19 is the key to disease management. ${ }^{3}$ In particular, the fall-winter season in the northern hemisphere which typically increases the co-circulation of other respiratory viruses, including influenza, which could render the difficulty of distinguishing COVID-19 from other respiratory diseases. Currently, naso/oropharyngeal swab sampling according to RNA extraction and RT-qPCR is the most common methods for SARS-CoV-2 detection. However, the naso/oropharyngeal swab procedure has several short-comings including nasal irritation, pain, and a requirement for technical skill (false-negative results may result from improper procedures). Furthermore, this procedure requires additional medical resources, such as personal protective equipment and sterile swabs. ${ }^{51}$ Considering these factors, the naso/oropharyngeal swab method is quite limited for mass screening or its use in 


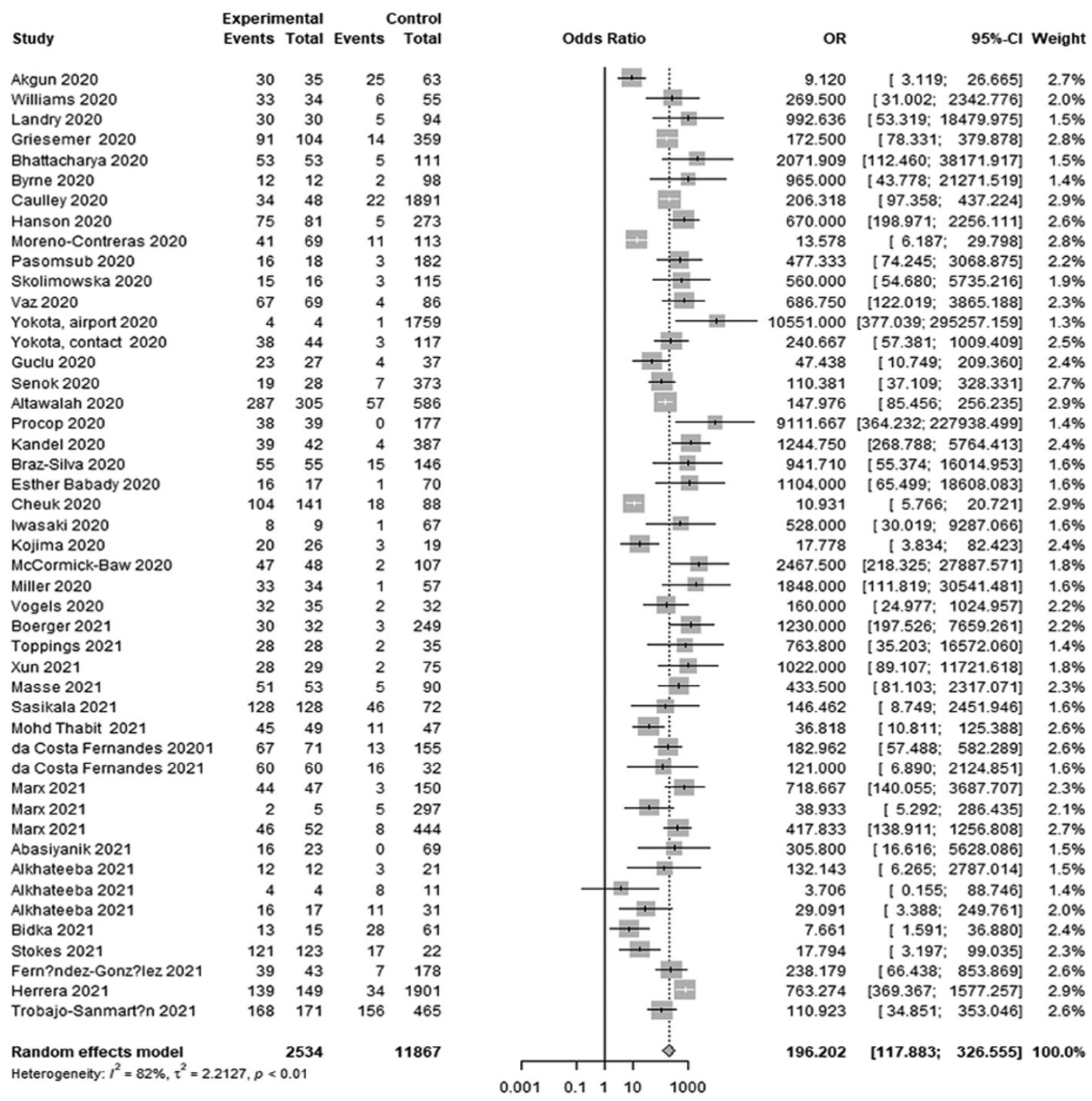

Figure 2 - Forest plot of the diagnostic odds ratios of the included studies.

developing countries. ${ }^{25}$ Therefore, there is an increasing need of an effective testing method for COVID-19 that is non-invasive, safe, comfortable, and requires minimal medical resources. ${ }^{52}$

Saliva samples have previously been proposed as diagnostic tools for detecting various respiratory virus infections, such as influenza viruses, respiratory cell fusion viruses, and SARS-CoV. Recent studies have shown that SARS-CoV-2 could also be diagnosed with saliva. ${ }^{25}$ In addition, saliva sampling reduces time and costs by eliminating the need for personal protection or virus-carrying solutions. ${ }^{16}$ Therefore, studies have been conducted to examine the diagnostic power of tests based on saliva sampling. ${ }^{7,8,10-26}$

Two previous meta-analyses evaluated the use of saliva to accurately diagnose COVID-19., ${ }^{9,53}$ The authors suggested that self-collected saliva can be used to diagnose COVID-19. However, there were some limitations to confirm the evidence. ${ }^{9,53}$ Due to the relatively small sample size, a comprehensive analysis and thorough investigation were difficult in previous analysis. ${ }^{9}$ The other analysis evaluated 8 additional 


\section{SROC curve (bivariate model)}

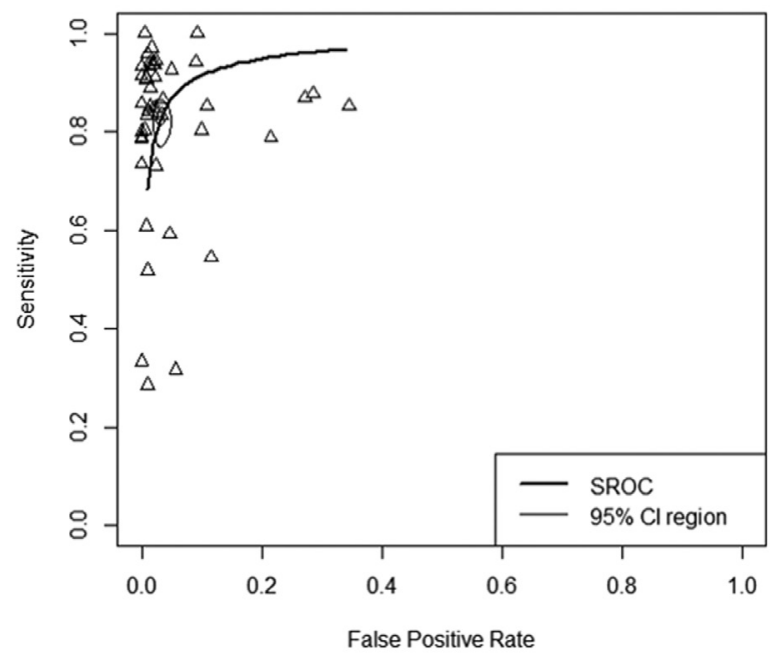

Figure 3 - Area under the summary receiver operating characteristic (SROC) curve of the included studies. CI: confidence interval

studies, but it had methodologic flaws. ${ }^{53}$ For example, only one author conducted the search and extracted data from the included studies, and there was no mention of the heterogeneity among the enrolled studies or the strategy for addressing the heterogeneity (for instance, subgroup analysis)..$^{53}$

Therefore, we did a bivariate meta-analysis with newly included studies focusing on the location and timing of sample harvest. The self-collected saliva samples were compared to samples collected by medical workers using naso/oropharyngeal swabs, and qualitative agreement between the saliva-based test and reference test was assessed. This information could be helpful for citizens to gain easy and early access to the test and for healthcare professionals to minimize the risk of SARS-CoV-2 transmission via specimen contact.

In this study, self-collected saliva testing yielded AUC of 0.955. The AUC was in the range of 0.9-1, suggesting excellent diagnostic accuracy. ${ }^{49}$ The virus utilizes the angiotensin converting enzyme 2 receptor for host entry, and it is also expressed at detectable levels in the salivary glands and ducts. ${ }^{54}$ In addition, salivary gland epithelial cells are early targets and the virus can dwell inside the cells during the first stage of infection. ${ }^{7,54}$ High correlation coefficients, indicating strong diagnostic agreement between the standard naso/oropharyngeal swab and the saliva collection sample, also could support the diagnostic power of the saliva samples.

However, our results showed that self-collected saliva samples had lower sensitivity and similar specificity compared with naso/oropharyngeal swab specimens for diagnosing COVID-19. This finding was consistent with the previous findings of Kivelä et al. ${ }^{53}$ Previous studies reported lower viral loads of SARS-CoV-2 in saliva than in corresponding nasopharyngeal swab specimens. ${ }^{7,15,54}$ The lower viral load in saliva may explain the higher rate of false negatives (decreasing sensitivity) compared with naso/oropharyngeal specimens. ${ }^{15,53}$ However, relatively low sensitivity of the saliva-based test is acceptable under certain conditions, considering that the saliva sampling test requires fewer medical consumable resources and professional personnel, and minimizes patient's discomfort. ${ }^{53}$

In this regard, one report recommended standardizing the sampling and testing methods for optimal clinical application of the saliva-based COVID-19 test. ${ }^{9}$ Our meta-analysis included various methods (saliva only vs. enhanced saliva [including lower pharyngeal and respiratory secretion]) and clinical conditions (asymptomatic vs. symptomatic examinees). Therefore, we carriedout a subgroup analyses according to different geography, saliva collection method, and existence or absence of symptoms. Interestingly, the saliva collection method did not show the significant influence in diagnostic accuracy. A previous study also reported similar results that there was no substantial difference between only oral saliva and enhanced saliva. ${ }^{55}$ In pathophysiology and time course, the main entry points of coronavirus are the nasal epithelial cells as well as the stratified squamous epithelium of oropharynx and laryngopharynx. ${ }^{56}$ Through oral-lung aspiration, the virus can spread from oral or nasal passage to the lower respiratory organs. In $80 \%$ of infected cases, the virus remains within the upper airway expressing mild symptoms. ${ }^{57}$ The enhanced saliva may contain both bronchopulmonary and nasopharyngeal secretions by coughing. The current knowledge of viral progression from proximal to distal airways might explain why oral saliva plus lower respiratory secretion seemed to have the similar diagnostic accuracy with oral saliva only in the community or mass screening. In particular, some patients would feel uncomfortable or have difficulty in coughing to produce mucus. However, simple collecting method such as drooling or spitting could help spread the usage of saliva test for COVID-19.

In addition, the viral loads of samples were significantly high during the first week of symptom development, then gradually decreased over time, and became undetectable approximately 2 weeks after symptom development. ${ }^{58}$ These patterns could indicate that the timing of sampling regarding diagnosis was likely to influence accuracy in asymptomatic as well 
Table 1 - Subgroup analysis of ethnicity, saliva collection method, and participants'symptoms.

\begin{tabular}{|c|c|c|c|c|c|c|c|}
\hline Subgroup & Study (n) & DOR & $\begin{array}{l}\text { Sensitivity } \\
95 \% \text { CIs } \\
\mathrm{I}^{2}\end{array}$ & Specificity & AUC & NPV & PPV \\
\hline $\begin{array}{l}\text { Self-collected saliva } \\
\text { (total) }\end{array}$ & 41 & $\begin{array}{c}196.2022 \\
{[117.8833-326.5546]} \\
82 \%\end{array}$ & $\begin{array}{c}0.8476 \\
{[0.8045-0.8826]} \\
87.3 \%\end{array}$ & $\begin{array}{c}0.9817 \\
{[0.9707-0.9887]} \\
89 \%\end{array}$ & 0.955 & $\begin{array}{c}0.9467 \\
{[0.9130-0.9678]} \\
96.4 \%\end{array}$ & $\begin{array}{c}0.9404 \\
{[0.9122-0.9599]} \\
83.2 \%\end{array}$ \\
\hline \multicolumn{8}{|l|}{ Regions } \\
\hline North America & 20 & $\begin{array}{c}250.4321 \\
{[120.4677-520.6066]} \\
81.1 \%\end{array}$ & $\begin{array}{c}0.8798 \\
{[0.8182-0.9224]} \\
84.5 \%\end{array}$ & $\begin{array}{c}0.9807 \\
{[0.9646-0.9896]} \\
87.2 \%\end{array}$ & & $\begin{array}{c}0.9635 \\
{[0.9265-0.9822]} \\
94.1 \%\end{array}$ & $\begin{array}{c}0.9275 \\
{[0.8801-0.9571]} \\
81.1 \%\end{array}$ \\
\hline Asia & 12 & $\begin{array}{c}92.3075 \\
{[35.8172-237.8934]} \\
85.6 \%\end{array}$ & $\begin{array}{c}0.7938 \\
{[0.6970-0.8656]} \\
87.1 \%\end{array}$ & $\begin{array}{c}0.9766 \\
{[0.9297-0.9924]} \\
94.7 \%\end{array}$ & & $\begin{array}{c}0.9283 \\
{[0.8056-0.9759]} \\
0.9283 \\
{[0.8056-0.9759]}\end{array}$ & $\begin{array}{c}0.9175 \\
{[0.8410-0.9589]} \\
0.9175 \\
{[0.8410-0.9589]}\end{array}$ \\
\hline Europe & 6 & $\begin{array}{c}212.1821 \\
{[117.6169-382.7785]} \\
0 \%\end{array}$ & $\begin{array}{c}0.8080 \\
{[0.6984-0.8844]} \\
82.4 \%\end{array}$ & $\begin{array}{c}0.9852 \\
{[0.9751-0.9912]} \\
0 \%\end{array}$ & & $\begin{array}{c}0.9143 \\
{[0.7872-0.9685]} \\
95 \%\end{array}$ & $\begin{array}{c}0.9676 \\
{[0.9369-0.9836]} \\
30.9 \%\end{array}$ \\
\hline South America & 2 & $\begin{array}{c}748.1044 \\
{[171.1188-3270.5945]} \\
0 \%\end{array}$ & $\begin{array}{c}0.8814 \\
{[0.7180-0.9559]} \\
71.2 \%\end{array}$ & $\begin{array}{c}0.9924 \\
{[0.9321-0.9992]} \\
35.1 \%\end{array}$ & & $\begin{array}{c}0.9189 \\
{[0.8642-0.9527]} \\
5.2 \%\end{array}$ & $\begin{array}{c}0.9839 \\
{[0.9378-0.9960]} \\
0 \%\end{array}$ \\
\hline Oceania & 1 & $\begin{array}{c}269.5000 \\
{[31.0018-2342.7756]} \\
\text { NA }\end{array}$ & $\begin{array}{c}0.8462 \\
{[0.6974-0.9292]} \\
\text { NA }\end{array}$ & $\begin{array}{c}0.9800 \\
{[0.8712-0.9972]} \\
\text { NA }\end{array}$ & & $\begin{array}{c}0.8909 \\
{[0.7777-0.9502]} \\
\text { NA }\end{array}$ & $\begin{array}{c}0.9706 \\
{[0.8186-0.9959]} \\
\text { NA }\end{array}$ \\
\hline$P$-value & & 0.1979 & 0.389 & 0.8652 & & 0.2833 & 0.079 \\
\hline \multicolumn{8}{|l|}{ Collection method } \\
\hline Only oral cavity saliva & 26 & $\begin{array}{c}215.1566 \\
{[110.2014-420.0706]} \\
84 \%\end{array}$ & $\begin{array}{c}0.8365 \\
{[0.7793-0.8812]} \\
87.4 \%\end{array}$ & $\begin{array}{c}0.9827 \\
{[0.9713-0.9896]} \\
84.4 \%\end{array}$ & & $\begin{array}{c}0.9496 \\
{[0.9111-0.9719]} \\
96.1 \%\end{array}$ & $\begin{array}{c}0.9367 \\
{[0.9007-0.9602]} \\
80.9 \%\end{array}$ \\
\hline $\begin{array}{l}\text { Only oral cavity saliva } \\
\text { (not defined) }\end{array}$ & 8 & $\begin{array}{c}237.4246 \\
{[61.4927-916.7010]} \\
85.2 \%\end{array}$ & $\begin{array}{c}0.8919 \\
{[0.8432-0.9268]} \\
28.7 \%\end{array}$ & $\begin{array}{c}0.9820 \\
{[0.9035-0.9969]} \\
96.3 \%\end{array}$ & & $\begin{array}{c}0.9731 \\
{[0.9269-0.9904]} \\
89.7 \%\end{array}$ & $\begin{array}{c}0.9173 \\
{[0.7993-0.9686]} \\
86.0 \%\end{array}$ \\
\hline Enhanced saliva & 7 & $\begin{array}{c}127.2254 \\
{[41.0992-393.8348]} \\
67.0 \%\end{array}$ & $\begin{array}{c}0.8353 \\
{[0.6844-0.9222]} \\
91.7 \%\end{array}$ & $\begin{array}{c}0.9779 \\
{[0.9338-0.9928]} \\
75.7 \%\end{array}$ & & $\begin{array}{c}0.8823 \\
{[0.6404-0.9693]} \\
2.0842\end{array}$ & $\begin{array}{c}0.9654 \\
{[0.9075-0.9875]} \\
70.9 \%\end{array}$ \\
\hline$P$-value & & 0.7001 & 0.2282 & 0.928 & & 0.2176 & 0.4355 \\
\hline \multicolumn{8}{|l|}{ Patient symptom } \\
\hline Symptomatic & 22 & $\begin{array}{c}245.6222 \\
{[111.2860-542.1192]} \\
80.6 \%\end{array}$ & $\begin{array}{c}0.8851 \\
{[0.8497-0.9130]} \\
71.0 \%\end{array}$ & $\begin{array}{c}0.9791 \\
{[0.9580-0.9898]} \\
87.3 \%\end{array}$ & & $\begin{array}{c}0.9522 \\
{[0.9124-0.9744]} \\
92.2 \%\end{array}$ & $\begin{array}{c}0.9495 \\
{[0.9103-0.9721]} \\
80.3 \%\end{array}$ \\
\hline Mixed & 15 & $\begin{array}{c}159.4638 \\
{[72.7019-349.7664]} \\
83.4 \%\end{array}$ & $\begin{array}{c}0.8208 \\
{[0.7399-0.8806]} \\
90.7 \%\end{array}$ & $\begin{array}{c}0.9783 \\
{[0.9588-0.9886]} \\
85.6 \%\end{array}$ & & $\begin{array}{c}0.9164 \\
{[0.8313-0.9606]} \\
97.0 \%\end{array}$ & $\begin{array}{c}0.9435 \\
{[0.9003-0.9687]} \\
82.4 \%\end{array}$ \\
\hline Asymptomatic & 4 & $\begin{array}{c}184.8991 \\
{[44.5856-766.7872]} \\
80.3 \%\end{array}$ & $\begin{array}{c}0.7049 \\
{[0.4705-0.8653]} \\
82.3 \%\end{array}$ & $\begin{array}{c}0.9933 \\
{[0.9673-0.9987]} \\
92.3 \%\end{array}$ & & $\begin{array}{c}0.9772 \\
{[0.8563-0.9968]} \\
97.0 \%\end{array}$ & $\begin{array}{c}0.8483 \\
{[0.6869-0.9345]} \\
71.2 \%\end{array}$ \\
\hline$P$-value & & 0.7469 & 0.03 & 0.3924 & & 0.329 & 0.0879 \\
\hline
\end{tabular}

DOR: diagnostic odds ratio, CI: confidence interval, AUC: area under the curve, NPV: negative predictive value, PPV: positive predictive value

as symptomatic patients. Caution is recommended when choosing diagnostic tests for screening in terms of the related timing to disease progression. ${ }^{58}$ Saliva self-collection for SARS-CoV-2 testing was reported not to be influenced by gender, age, race/ethnicity, or educational level in the United States. ${ }^{19}$ There was no significant heterogeneity of diagnostic accuracy among geographic locations. However, our classification according to geographic location included only one or 2 studies in South America and Oceania. Therefore, future prospective studies with larger numbers of patients evenly grouped by geographic location are needed to analyze the effect of geographic location on the results of test using self-collected saliva.

Study limitations. First, the collected data showed significant heterogeneity that required random effect 
models and subgroup analysis. One possible explanation is that RT-qPCR in naso/oropharyngeal samples, which is used as the main diagnostic tool for COVID-19, shows a wide range in sensitivity (56-83\%). ${ }^{59}$ This might have led to misclassification and diagnostic bias, causing heterogeneity. Secondly, the nature of crosssectional designs can over- or under-estimate the real prevalence. Thirdly, there was a lack of methodological homogeneity and inadequate reporting of methods. ${ }^{9}$

In conclusion, this study indicated that RT-qPCR detects SARS-CoV-2 with lower sensitivity using self-collected saliva compared to conventional naso/oropharyngeal samples. However, saliva samples are easily obtained by drooling or spitting in a sample container. The saliva-based test has the advantage of not requiring healthcare workers or personal protective equipment for sample collection. This advantage could be useful in situations in which mass screening is needed or medical resources are scarce.

Acknowledgment. The authors gratefully acknowledge Textcheck (www.textcheck.com) for English language editing.

\section{References}

1. Joffily L, Ungierowicz A, David AG, Melo B, Brito CLT, Mello $\mathrm{L}$, et al. The close relationship between sudden loss of smell and COVID-19. Braz J Otorbinolaryngol 2020; 86: 632-638.

2. Zayet S, Klopfenstein T, Mercier J, Kadiane-Oussou NJ, Lan Cheong Wah L, Royer PY, et al. Contribution of anosmia and dysgeusia for diagnostic of COVID-19 in outpatients. Infection 2021; 49: 361-365.

3. Yan $\mathrm{CH}$, Faraji F, Prajapati DP, Boone CE, DeConde AS. Association of chemosensory dysfunction and COVID-19 in patients presenting with influenza-like symptoms. Int Forum Allergy Rhinol 2020; 10: 806-813.

4. Kang SJ, Jung SI. Age-related morbidity and mortality among patients with COVID-19. Infect Chemother 2020; 52: 154-164.

5. Liu M, Li Q, Zhou J, Ai W, Zheng X, Zeng J, et al. Value of swab types and collection time on SARS-COV-2 detection using RT-PCR assay. J Virol Methods 2020; 286: 113974.

6. Mohammadi A, Esmaeilzadeh E, Li Y, Bosch RJ, Li JZ. SARS-CoV-2 detection in different respiratory sites: a systematic review and meta-analysis. EBioMedicine 2020; 59: 102903.

7. Pasomsub E, Watcharananan SP, Boonyawat K, Janchompoo P, Wongtabtim G, Suksuwan W, et al. Saliva sample as a noninvasive specimen for the diagnosis of coronavirus disease 2019: a cross-sectional study. Clin Microbiol Infect 2021; 27: 285.

8. Yokota I, Shane PY, Okada K, Unoki Y, Yang Y, Inao T, et al. Mass screening of asymptomatic persons for severe acute respiratory syndrome coronavirus 2 using saliva. Clin Infect Dis 2021; 73: e559-e565.

9. Czumbel LM, Kiss S, Farkas N, Mandel I, Hegyi A, Nagy Á, et al. Saliva as a candidate for COVID-19 diagnostic testing: a meta-analysis. Front Med (Lausanne) 2020; 7: 465.

10. Williams E, Bond K, Zhang B, Putland M, Williamson DA. Saliva as a noninvasive specimen for detection of SARS-CoV-2. J Clin Microbiol 2020; 58: e00776-e00720.
11. Skolimowska K, Rayment M, Jones R, Madona P, Moore LSP, Randell P. Non-invasive saliva specimens for the diagnosis of COVID-19: caution in mild outpatient cohorts with low prevalence. Clin Microbiol Infect 2020; 26: 1711-1713.

12. Moreno-Contreras J, Espinoza MA, Sandoval-Jaime C, CantúCuevas MA, Barón-Olivares H, Ortiz-Orozco OD, et al. Saliva sampling and its direct lysis, an excellent option to increase the number of SARS-CoV-2 diagnostic tests in settings with supply shortages. J Clin Microbiol 2020; 58: e01659-e01620.

13. Landry ML, Criscuolo J, Peaper DR. Challenges in use of saliva for detection of SARS CoV-2 RNA in symptomatic outpatients. J Clin Virol 2020; 130: 104567.

14. Hanson KE, Barker AP, Hillyard DR, Gilmore N, Barrett JW, Orlandi RR, et al. Self-collected anterior nasal and saliva specimens versus health care worker-collected nasopharyngeal swabs for the molecular detection of SARS-CoV-2. J Clin Microbiol 2020; 58: e01824-e01820.

15. Procop GW, Shrestha NK, Vogel S, Van Sickle K, Harrington $S$, Rhoads DD, et al. A direct comparison of enhanced saliva to nasopharyngeal swab for the detection of SARS-CoV-2 in symptomatic patients. J Clin Microbiol 2020; 58: e01946e01920.

16. Vaz SN, Santana DS, Netto EM, Pedroso C, Wang WK, Santos FDA, et al. Saliva is a reliable, non-invasive specimen for SARS-CoV-2 detection. Braz J Infect Dis 2020; 24: 422-427.

17. Güçlü E, Koroglu M, Yürümez Y, Toptan H, Kose E, Güneysu F, et al. Comparison of saliva and oro-nasopharyngeal swab sample in the molecular diagnosis of COVID-19. Rev Assoc Med Bras (1992) 2020; 66: 1116-1121.

18. Altawalah H, AlHuraish F, Alkandari WA, Ezzikouri S. Saliva specimens for detection of severe acute respiratory syndrome coronavirus 2 in Kuwait: a cross-sectional study. J Clin Virol 2020; 132: 104652.

19. Griesemer SB, Van Slyke G, Ehrbar D, Strle K, Yildirim T, Centurioni DA, et al. Evaluation of specimen types and saliva stabilization solutions for SARS-CoV-2 testing. J Clin Microbiol 2021; 59: e01418-e01420.

20. Caulley L, Corsten M, Eapen L, Whelan J, Angel JB, Antonation $\mathrm{K}$, et al. Salivary detection of COVID-19. Ann Intern Med 2021; 174: 131-133.

21. Senok A, Alsuwaidi H, Atrah Y, Al Ayedi O, Al Zahid J, Han A, et al. Saliva as an alternative specimen for molecular COVID-19 testing in community settings and population-based screening. Infect Drug Resist 2020; 13: 3393-3399.

22. Babady NE, McMillen T, Jani K, Viale A, Robilotti EV, Aslam $A$, et al. Performance of severe acute respiratory syndrome coronavirus 2 real-time RT-PCR tests on oral rinses and saliva samples. J Mol Diagn 2021; 23: 3-9.

23. Kandel C, Zheng J, McCready J, Serbanescu MA, Racher H, Desaulnier M, et al. Detection of SARS-CoV-2 from saliva as compared to nasopharyngeal swabs in outpatients. Viruses 2020; 12: 1314.

24. Braz-Silva PH, Mamana AC, Romano CM, Felix AC, de Paula AV, Fereira NE, et al. Performance of at-home self-collected saliva and nasal-oropharyngeal swabs in the surveillance of COVID-19. J Oral Microbiol 2020; 13: 1858002.

25. Bhattacharya D, Parai D, Rout UK, Nanda RR, Kanungo S, Dash GC, et al. Saliva as a potential clinical specimen for diagnosis of SARS-CoV-2. MedRxiv 2020; 9: 20192591. 
26. Byrne RL, Kay GA, Kontogianni K, Brown L, Collins AM, Cuevas LE, et al. Saliva offers a sensitive, specific and noninvasive alternative to upper respiratory swabs for SARS-CoV-2 diagnosis. medRxiv 2020; 9: 20149534.

27. Dogan OA, Kose B, Agaoglu NB, Yildiz J, Alkurt G, Demirkol $\mathrm{YK}$, et al. Does sampling saliva increase detection of SARS-CoV-2 by RT-PCR? comparing saliva with oro-nasopharyngeal swabs. J Virol Methods 2021; 290: 114049.

28. Wong SCY, Tse H, Siu HK, Kwong TS, Chu MY, Yau FYS, et al. Posterior oropharyngeal saliva for the detection of severe acute respiratory syndrome coronavirus 2 (SARS-CoV-2). Clin Infect Dis 2020; 71: 2939-2946.

29. Iwasaki S, Fujisawa S, Nakakubo S, Kamada K, Yamashita Y, Fukumoto T, et al. Comparison of SARS-CoV-2 detection in nasopharyngeal swab and saliva. J Infect 2020; 81: e145-e147.

30. Kojima N, Turner F, Slepnev V, Bacelar A, Deming L, Kodeboyina S, et al. Self-collected oral fluid and nasal swabs demonstrate comparable sensitivity to clinician collected nasopharyngeal swabs for coronavirus disease 2019 detection. Clin Infect Dis 2021; 73: e3106-e3109.

31. McCormick-Baw C, Morgan K, Gaffney D, Cazares Y, Jaworski K, Byrd A, et al. Saliva as an alternate specimen source for detection of SARS-CoV-2 in symptomatic patients using Cepheid Xpert Xpress SARS-CoV-2. J Clin Microbiol 2020; 58: e01109-e01120.

32. Miller M, Jansen M, Bisignano A, Mahoney S, Wechsberg C, Albanese $\mathrm{N}$, et al. Validation of a self-administrable, salivabased RT-qPCR test detecting SARS-CoV-2. MedRxiv 2020; 6: 20122721.

33. Vogels CBF, Watkins AE, Harden CA, Brackney DE, Shafer J, Wang J, et al. SalivaDirect: a simplified and flexible platform to enhance SARS-CoV-2 testing capacity. $\operatorname{Med}$ (NY) 2021; 2: 263-280.

34. Boerger AC, Buckwalter S, Fernholz EC, Jannetto PJ, Binnicker MJ, Reed K, et al. Evaluation of self-collected midturbinate nasal swabs and saliva for detection of SARS-CoV-2 RNA. $J$ Clin Microbiol 2021; 59: e0084821.

35. Toppings NB, Mohon AN, Lee Y, Kumar H, Lee D, Kapoor $\mathrm{R}$, et al. A rapid near-patient detection system for SARS-CoV-2 using saliva. Sci Rep 2021; 11: 13378.

36. Xun G, Lane ST, Petrov VA, Pepa BE, Zhao H. A rapid, accurate, scalable, and portable testing system for COVID-19 diagnosis. Nat Commun 2021; 12: 2905.

37. Masse S, Bonnet C, Vilcu AM, Benamar H, Swital M, van der Werf S, et al. Are posterior oropharyngeal saliva specimens an acceptable alternative to nasopharyngeal sampling for the monitoring of SARS-CoV-2 in primary-care settings? Viruses 2021; 13: 761.

38. Sasikala M, Sadhana Y, Vijayasarathy K, Gupta A, Daram SK, Podduturi NCR, et al. Comparison of saliva with healthcare workers- and patient-collected swabs in the diagnosis of COVID-19 in a large cohort. BMC Infect Dis 2021; 21: 648.

39. Mohd Thabit AA, Peariasamy KM, Kuan PX, Fern Ying DK, Nheu N, Cyncynatus C, et al. Diagnostic accuracy of fresh drooled saliva for SARS-CoV-2 in travelers. Travel Med Infect Dis 2021; 43: 102144.

40. Fernandes PADC, Ferreira FADC, Morais OM, Ramos CMT, Fernandes ÉMR, Rocha SAAD, et al. Performance of saliva as a specimen to detect SARS-CoV-2. J Clin Virol 2021; 142: 104913.
41. Marx GE, Biggerstaff BJ, Nawrocki CC, Totten SE, Travanty EA, Burakoff AW, et al. Detection of severe acute respiratory syndrome coronavirus 2 on self-collected saliva or anterior nasal specimens compared with healthcare personnel-collected nasopharyngeal specimens. Clin Infect Dis 2021; 73: S65-S73.

42. Abasiyanik MF, Flood B, Lin J, Ozcan S, Rouhani SJ, Pyzer A, et al. Sensitive detection and quantification of SARS-CoV-2 in saliva. Sci Rep 2021; 11: 12425.

43. Alkhateeb KJ, Cahill MN, Ross AS, Arnold FW, Snyder JW. The reliability of saliva for the detection of SARS-CoV-2 in symptomatic and asymptomatic patients: insights on the diagnostic performance and utility for COVID-19 screening. Diagn Microbiol Infect Dis 2021; 101: 115450.

44. Bidkar V, Mishra M, Gade N, Selvaraj K. Conventional nasooropharyngeal sampling versus self-collected saliva samples in COVID-19 testing. Indian J Otolaryngol Head Neck Surg 2021: 1-7.

45. Stokes W, Berenger BM, Portnoy D, Scott B, Szelewicki J, Singh T, et al. Clinical performance of the Abbott Panbio with nasopharyngeal, throat, and saliva swabs among symptomatic individuals with COVID-19. Eur J Clin Microbiol Infect Dis 2021; 40: 1721-1726.

46. Fernández-González $\mathrm{M}$, Agulló V, de la Rica A, Infante A, Carvajal M, García JA, et al. Performance of saliva specimens for the molecular detection of SARS-CoV-2 in the community setting: does sample collection method matter? J Clin Microbiol 2021; 59: e03033-e03020.

47. Trobajo-Sanmartín C, Adelantado M, Navascués A, Guembe MJ, Rodrigo-Rincón I, Castilla J, et al. Self-collection of saliva specimens as a suitable alternative to nasopharyngeal swabs for the diagnosis of SARS-CoV-2 by RT-qPCR. J Clin Med 2021; 10: 299.

48. Herrera LA, Hidalgo-Miranda A, Reynoso-Noverón N, Meneses-García AA, Mendoza-Vargas A, Reyes-Grajeda JP, et al. Saliva is a reliable and accessible source for the detection of SARS-CoV-2. Int J Infect Dis 2021; 105: 83-90.

49. Kim DH, Kim Y, Kim SW, Hwang SH. Use of narrowband imaging for the diagnosis and screening of laryngeal cancer: a systematic review and meta-analysis. Head Neck 2020; 42 : 2635-2643.

50. Meseguer-Henarejos AB, Sánchez-Meca J, López-Pina JA, Carles-Hernández R. Inter- and intra-rater reliability of the modified Ashworth scale: a systematic review and meta-analysis. Eur J Phys Rehabil Med 2018; 54: 576-590.

51. Sakanashi D, Asai N, Nakamura A, Miyazaki N, Kawamoto Y, Ohno T, et al. Comparative evaluation of nasopharyngeal swab and saliva specimens for the molecular detection of SARS-CoV-2 RNA in Japanese patients with COVID-19. J Infect Chemother 2021; 27: 126-129.

52. Rao M, Rashid FA, Sabri FSAH, Jamil NN, Zain R, Hashim $\mathrm{R}$, et al. Comparing nasopharyngeal swab and early morning saliva for the identification of severe acute respiratory syndrome coronavirus 2 (SARS-CoV-2). Clin Infect Dis 2021; 72: e352-e356.

53. Kivelä JM, Jarva H, Lappalainen M, Kurkela S. Saliva-based testing for diagnosis of SARS-CoV-2 infection: a meta-analysis. J Med Virol 2021; 93: 1256-1258.

54. Chen L, Zhao J, Peng J, Li X, Deng X, Geng Z, et al. Detection of SARS-CoV-2 in saliva and characterization of oral symptoms in COVID-19 patients. Cell Prolif 2020; 53: e12923. 
55. Lee RA, Herigon JC, Benedetti A, Pollock NR, Denkinger CM. Performance of saliva, oropharyngeal swabs, and nasal swabs for SARS-CoV-2 molecular detection: a systematic review and meta-analysis. J Clin Microbiol 2021; 59: e02881-e02820.

56. Gentzsch M, Rossier BC. A pathophysiological model for COVID-19: critical importance of transepithelial sodium transport upon airway infection. Function (Oxf) 2020; 1: zqaa024.

57. Roque M, Proudfoot K, Mathys V, Yu S, Krieger N, Gernon $T$, et al. A review of nasopharyngeal swab and saliva tests for SARS-CoV-2 infection: disease timelines, relative sensitivities, and test optimization. J Surg Oncol 2021; 124: 465-475.
58. Kociolek LK, Muller WJ, Yee R, Dien Bard J, Brown CA, Revell PA, et al. Comparison of upper respiratory viral load distributions in asymptomatic and symptomatic children diagnosed with SARS-CoV-2 infection in pediatric hospital testing programs. J Clin Microbiol 2020; 59: e02593-e02520.

59. Zayet S, Klopfenstein T, Mercier J, Kadiane-Oussou NJ, Lan Cheong Wah L, Royer PY, et al. Contribution of anosmia and dysgeusia for diagnostic of COVID-19 in outpatients. Infection 2021; 49: 361-365. 
Saliva tests for COVID-19 ... Kim et al

Appendix 1 - Participants, interventions, comparisons, outcomes, timings, and study design (PICOTS).

\begin{tabular}{lc}
\hline PICOTS component & Details \\
\hline Participants & Patients with COVID-19 suspected symptoms or asymptomatic population screening \\
Interventions & Saliva specimens RT-qPCR results of detect SARS-CoV-2 \\
Comparisons & Naso/oropharyngeal specimens RT-qPCR results of detect SARS-CoV-2 \\
Outcomes & Diagnostic accuracy, specificities, and negative predictive values analysis \\
Timings & From inception to August 2021 \\
Study design & A systematic review and meta-analysis \\
\hline \multicolumn{1}{c}{ COVID-19: coronavirus disease-19, RT-qPCR: reverse transcription quantitative polymerase chain reaction, SARS-CoV-2: severe acute respiratory } \\
\end{tabular}


Appendix 2 - Study characteristics.

\begin{tabular}{|c|c|c|c|c|c|c|c|c|c|c|c|c|}
\hline Study & Study design & Number & $\begin{array}{l}\text { Gender } \\
\text { (male/ } \\
\text { female) }\end{array}$ & $\begin{array}{c}\text { Age (years), } \\
\text { median (range) } \\
\text { or mean } \pm S D\end{array}$ & Nationality & Participants & $\begin{array}{l}\text { Collecting } \\
\text { method }\end{array}$ & Correlation & TP & FN & $\mathrm{FP}$ & TN \\
\hline Williams et al, ${ }^{10}$ & case-control & 89 & NR & NR & Australia & & Only oral cavity & & 33 & 6 & 1 & 49 \\
\hline Landry et $\mathrm{al}^{13}$ & & 124 & NR & NR & USA & symptomatic & saliva & 0.851 & 30 & 5 & 0 & 89 \\
\hline Griesemer et al, ${ }^{19}$ & cohort & 463 & $246 / 117$ & $14-77$ & USA & mixed & Oral cavity saliva & & 91 & 14 & 13 & 345 \\
\hline $\begin{array}{l}\text { Bhattacharya et } \\
\mathrm{al}^{25}\end{array}$ & case-control & 74 & NR & NR & India & symptomatic & $\begin{array}{l}\text { (not defined) } \\
\text { (nal cavity saliva }\end{array}$ & & 53 & 5 & 0 & 106 \\
\hline Byrne et $\mathrm{al}^{26}$ & & 110 & $61 / 49$ & NR & England & & & & 12 & 2 & 0 & 96 \\
\hline Caulley et al, ${ }^{20}$ & & 1939 & NR & NR & Canada & mixed & Only oral cavity & & 34 & 22 & 14 & 1869 \\
\hline Hanson et $\mathrm{al},{ }^{14}$ & cohort & 354 & $188 / 166$ & $35(18-75)$ & USA & & & 0.912 & 75 & 5 & 6 & 268 \\
\hline $\begin{array}{l}\text { Moreno-Contreras } \\
\text { et } \mathrm{al}^{12}\end{array}$ & & 182 & $116 / 137$ & $41 \pm 14.4$ & Mexico & & $\begin{array}{l}\text { Oral cavity saliva } \\
\text { (not defined) }\end{array}$ & & 41 & 11 & 28 & 102 \\
\hline Pasomsub et al, ${ }^{7}$ & cross-sectional & 200 & $69 / 131$ & $36(28-48)$ & Thailand & symptomatic & & 0.851 & 16 & 3 & 2 & 179 \\
\hline $\begin{array}{l}\text { Skolimowska et } \\
{\mathrm{al},{ }^{11}}^{1}\end{array}$ & & 131 & $43 / 89$ & $39(30-51)$ & England & & $\begin{array}{l}\text { Only oral cavity } \\
\text { saliva }\end{array}$ & & 15 & 3 & 1 & 112 \\
\hline Vaz et al, ${ }^{16}$ & & 155 & $46 / 103$ & $40(33-48.5)$ & Brazil & & & 0.922 & 67 & 4 & 2 & 82 \\
\hline $\begin{array}{l}\text { Yokota et al, } \\
\text { (airport) }\end{array}$ & cohort & 1763 & $\begin{array}{l}927 / 832 / 4 \\
\text { (unknown) }\end{array}$ & $33.5(22.6-47.4)$ & Japan & & & & 4 & 1 & 0 & 1758 \\
\hline $\begin{array}{l}\text { Yokota et al, }{ }^{8} \\
\text { (contact) }\end{array}$ & & 161 & $\begin{array}{l}\text { 44/26/91 } \\
\text { (unknown) }\end{array}$ & $44.9(29.8-66.4)$ & Japan & asymptomatic & $\begin{array}{l}\text { Oral cavity saliva } \\
\text { (not defined) }\end{array}$ & & 38 & 3 & 6 & 114 \\
\hline Güçlü et al, ${ }^{17}$ & & 64 & $37 / 27$ & $51.04 \pm 17.9$ & Turkey & symptomatic & & 0.744 & 23 & 4 & 4 & 33 \\
\hline Senok et al, ${ }^{21}$ & cross-sectional & 401 & $329 / 72$ & $35.5 \pm 9.5$ & UAE & asymptomatic & $\begin{array}{l}\text { Only oral cavity } \\
\text { saliva }\end{array}$ & 0.68 & 19 & 7 & 9 & 366 \\
\hline Altawalah et al, ${ }^{18}$ & & 891 & NR & NR & Kuwait & symptomatic & E ph & 0.814 & 287 & 57 & 18 & 529 \\
\hline Procop et $\mathrm{al},{ }^{15}$ & & 224 & NR & NR & USA & symptomatic & Enhanced salıva & & 38 & 0 & 1 & 177 \\
\hline Kandel et al, ${ }^{23}$ & & 429 & $295 / 134$ & $42(30-54)$ & Canada & mixed & Only oral cavity & 0.91 & 39 & 4 & 3 & 383 \\
\hline Braz-Silva et al, ${ }^{24}$ & cohort & 201 & $75 / 126$ & $40(31-52)$ & Brazil & & saliva & & 55 & 15 & 0 & 131 \\
\hline Babady et $\mathrm{al}^{22}$ & & 87 & NR & NR & USA & symptomatic & Enhanced saliva & & 16 & 1 & 1 & 69 \\
\hline Dogan et al, ${ }^{27}$ & cross-sectional & 98 & NR & NR & Turkey & & & & 30 & 25 & 5 & 38 \\
\hline Wong et $\mathrm{al}^{28}$ & retrospective & 229 & NR & NR & China & mixed & Only oral cavity & & 104 & 18 & 37 & 70 \\
\hline Iwasaki et $\mathrm{al}^{29}$ & cross-sectional & 66 & NR & NR & Japan & & & 0.874 & 8 & 1 & 1 & 66 \\
\hline Kojima et $\mathrm{al}^{30}$ & & 45 & NR & $45(21-53)$ & USA & & Enhanced saliva & & 20 & 3 & 6 & 16 \\
\hline $\begin{array}{l}\text { McCormick-Baw } \\
\text { et } \mathrm{al}^{31}\end{array}$ & $\begin{array}{c}\text { prospective } \\
\text { cross-sectional }\end{array}$ & 155 & NR & NR & USA & symptomatic & $\begin{array}{l}\text { Only oral cavity } \\
\text { saliva (not } \\
\text { defined) }\end{array}$ & & 47 & 2 & 1 & 105 \\
\hline Miller et al, ${ }^{32}$ & cross-sectional & 91 & NR & NR & USA & & $\begin{array}{l}\text { Only oral cavity } \\
\text { saliva }\end{array}$ & & 33 & 1 & 1 & 56 \\
\hline Vogels et al, ${ }^{33}$ & $\begin{array}{c}\text { prospective } \\
\text { cross-sectional }\end{array}$ & 67 & NR & NR & USA & mixed & $\begin{array}{l}\text { Only oral cavity } \\
\text { saliva (not } \\
\text { defined) }\end{array}$ & & 32 & 2 & 3 & 30 \\
\hline Boerger et $\mathrm{al},{ }^{34}$ & & 281 & NR & NR & USA & & & & 30 & 3 & 2 & 246 \\
\hline Toppings et al, ${ }^{35}$ & crese-sectional & 63 & NR & NR & Canada & & Only oral cavity & & 28 & 2 & 0 & 33 \\
\hline Xun et $\mathrm{al}^{36}$ & cross-sectional & 104 & NR & NR & USA & & & & 28 & 2 & 1 & 73 \\
\hline Masse et $\mathrm{al},{ }^{37}$ & & 143 & $63 / 80$ & $35(22.5-49)$ & France & symptomatic & 5 b d l. & 0.89 & 51 & 5 & 2 & 85 \\
\hline Sasikala et al, ${ }^{38}$ & prospective & 200 & $140 / 60$ & $37.9 \pm 12.8$ & India & & Enhanced saliva & & 128 & 46 & 0 & 26 \\
\hline 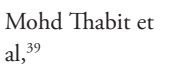 & cross-sectional & 96 & $66 / 30$ & $34 \pm 26(12-95)$ & Malaysia & mixed & & 0.69 & 45 & 11 & 4 & 36 \\
\hline Fernandes et al, ${ }^{40}$ & cohort & 226 & $91 / 135$ & NR & Portugal & & Only oral cavity & & 67 & 13 & 4 & 142 \\
\hline Marx et al, ${ }^{41}$ & cross-sectional & 730 & $420 / 310$ & NR & USA & $\begin{array}{l}\text { symptomatic/ } \\
\text { mixed/ } \\
\text { asymptomatic }\end{array}$ & saliva & 0.92 & 46 & 8 & 6 & 436 \\
\hline Abasiyanik et al, ${ }^{42}$ & cohort & 92 & NR & $45(30.58)$ & USA & symptomatic & & & 16 & 0 & 7 & 69 \\
\hline Alkhateeb et al, ${ }^{43}$ & $\begin{array}{c}\text { prospective } \\
\text { cross-sectional }\end{array}$ & 48 & $26 / 22$ & $39.9 \pm 15.5$ & USA & $\begin{array}{l}\text { symptomatic/ } \\
\text { mixed/ } \\
\text { asymptomatic }\end{array}$ & Enhanced saliva & & 12 & 3 & 0 & 18 \\
\hline Bidkar et al, ${ }^{44}$ & cross-sectional & 80 & $49 / 31$ & 36.4 & India & mixed & & & 13 & 28 & 2 & 33 \\
\hline Stokes et $\mathrm{al}{ }^{45}$ & & 145 & $75 / 70$ & 39.4 & Canada & symptomatic & & & 121 & 17 & 2 & 5 \\
\hline $\begin{array}{l}\text { Fernández- } \\
\text { González et al, }{ }^{46}\end{array}$ & $\begin{array}{l}\text { prospective } \\
\text { cross-sectional }\end{array}$ & 229 & $91 / 128$ & $39(21-48)$ & Spain & mixed & Only oral cavity & 0.85 & 39 & 7 & 4 & 171 \\
\hline Herrera et al, ${ }^{48}$ & $\begin{array}{l}\text { cross-sectional } \\
\text { study }\end{array}$ & 2107 & NR & NR & Mexico & asymptomatic & saliva & 0.852 & 139 & 34 & 10 & 1867 \\
\hline $\begin{array}{l}\text { Trobajo-Sanmartín } \\
\text { et al, }{ }^{47}\end{array}$ & $\begin{array}{c}\text { prospective } \\
\text { cross-sectional }\end{array}$ & 674 & $374 / 300$ & NR & Spain & mixed & & & 168 & 156 & 3 & 309 \\
\hline
\end{tabular}


Saliva tests for COVID-19 ... Kim et al

Appendix 3 - Methodological quality of all included studies..

\begin{tabular}{|c|c|c|c|c|c|c|c|}
\hline \multirow[t]{2}{*}{ Reference } & \multicolumn{4}{|c|}{ Risk of bias } & \multicolumn{3}{|c|}{ Concerns about application } \\
\hline & Patient selection & Index test & Reference standard & Flow and timing & Patient selection & Index test & Reference standard \\
\hline Williams et al, ${ }^{10}$ & Low & Low & Low & Low & Low & Low & Low \\
\hline Landry et $\mathrm{al}^{13}$ & Low & Low & Low & Unclear & Low & Low & Low \\
\hline Griesemer et al, ${ }^{19}$ & Low & Low & Low & Low & Low & Unclear & Low \\
\hline Bhattacharya et $\mathrm{al}{ }^{25}$ & Low & Low & Low & Unclear & Low & Unclear & Low \\
\hline Byrne et $\mathrm{al}_{,}{ }^{26}$ & Low & Low & Low & Low & Low & Low & Low \\
\hline Caulley et $\mathrm{al},{ }^{20}$ & Low & Low & Low & Unclear & Low & Low & Low \\
\hline Hanson et $\mathrm{al}^{14}$ & Low & Low & Low & Unclear & Low & Low & Low \\
\hline Moreno-Contreras et al, ${ }^{12}$ & Low & Low & Low & Unclear & Low & Unclear & Low \\
\hline Pasomsub et $\mathrm{al}^{7}$ & Low & Low & Low & Low & Low & Low & Low \\
\hline Skolimowska et al, ${ }^{11}$ & Low & Low & Low & Unclear & Low & Low & Low \\
\hline Vaz et $\mathrm{al}^{16}$ & Low & Low & Low & Low & Low & Low & Low \\
\hline Yokota et $\mathrm{al}^{8}{ }^{8}$ & Low & Low & Low & Unclear & Low & Unclear & Low \\
\hline Güçlü et al, ${ }^{17}$ & Low & Low & Low & Low & Low & Unclear & Low \\
\hline Senok et al, ${ }^{21}$ & Low & Low & Low & High & Low & Low & Low \\
\hline Altawalah et $\mathrm{al}^{18}$ & Low & Low & Low & High & Low & Low & Low \\
\hline Procop et $\mathrm{al},{ }^{15}$ & Low & Low & Low & Unclear & Low & Low & Low \\
\hline Kandel et al, ${ }^{23}$ & Low & Low & Low & Low & Low & Low & Low \\
\hline Braz-Silva et al, ${ }^{24}$ & Low & Low & Low & Unclear & Low & Low & Low \\
\hline Babady et al, ${ }^{22}$ & Unclear & Low & Low & Unclear & Low & Low & Low \\
\hline Dogan et $a l,{ }^{27}$ & Low & Low & Low & Unclear & Low & Unclear & Low \\
\hline Wong et $\mathrm{al}^{28}$ & Low & Low & Low & Low & Low & Low & Low \\
\hline Iwasaki et al, ${ }^{29}$ & Low & Low & Low & Unclear & Low & Low & Low \\
\hline Kojima et al,,$^{30}$ & Low & Low & Low & Low & Low & Low & Low \\
\hline McCormick-Baw et al, ${ }^{31}$ & Low & Low & Low & Unclear & Low & Unclear & Low \\
\hline Miller et al, ${ }^{32}$ & Low & Low & Low & Low & Low & Unclear & Low \\
\hline Vogels et al, ${ }^{33}$ & Low & Low & Low & High & Low & Low & Low \\
\hline Boerger et al, ${ }^{34}$ & Low & Low & Low & High & Low & Low & Low \\
\hline Toppings et al, ${ }^{35}$ & Low & Low & Low & Unclear & Low & Low & Low \\
\hline Xun et $\mathrm{al}^{36}$ & Low & Low & Low & Low & Low & Low & Low \\
\hline Masse et $\mathrm{al},{ }^{37}$ & Low & Low & Low & Unclear & Low & Low & Low \\
\hline Sasikala et al, ${ }^{38}$ & Unclear & Low & Low & Unclear & Low & Low & Low \\
\hline Mohd Thabit et al, ${ }^{39}$ & Low & Low & Low & Unclear & Low & Unclear & Low \\
\hline Fernandes et $\mathrm{al}{ }^{40}$ & Low & Low & Low & Low & Low & Low & Low \\
\hline Marx et al, ${ }^{41}$ & Low & Low & Low & Unclear & Low & Low & Low \\
\hline Abasiyanik et al, ${ }^{42}$ & Low & Low & Low & Low & Low & Low & Low \\
\hline Alkhateeb et $\mathrm{al}^{43}$ & Low & Low & Low & Unclear & Low & Unclear & Low \\
\hline Bidkar et $\mathrm{al}{ }^{44}$ & Low & Low & Low & Low & Low & Unclear & Low \\
\hline Stokes et $\mathrm{al}^{45}$ & Low & Low & Low & High & Low & Low & Low \\
\hline $\begin{array}{l}\text { Fernández-González et } \\
\mathrm{al}^{46}\end{array}$ & Low & Low & Low & High & Low & Low & Low \\
\hline Herrera et $\mathrm{al}^{48}$ & Low & Low & Low & Unclear & Low & Low & Low \\
\hline Trobajo-Sanmartín et al, ${ }^{47}$ & Low & Low & Low & Low & Low & Low & Low \\
\hline
\end{tabular}


Appendix 4 - Forest plots of the sensitivity of the included studies.

Study

Akgun 2020

Williams 2020

Landry 2020

Griesemer 2020

Bhattacharya 2020

Byrne 2020

Caulley 2020

Hanson 2020

Moreno-Contreras 2020

Pasomsub 2020

Skolimowska 2020

Vaz 2020

Yokota, airport 2020

Yokota, contact 2020

Guclu 2020

Senok 2020

Altawalah 2020

Procop 2020

Kandel 2020

Braz-Silva 2020

Esther Babady 2020

Cheuk 2020

Iwasaki 2020

Kojima 2020

McCormick-Baw 2020

Miller 2020

Vogels 2020

Boerger 2021

Toppings 2021

Xun 2021

Masse 2021

Sasikala 2021

Mohd Thabit 2021

da Costa Fernandes 20201

da Costa Fernandes 2021

Marx 2021

Marx 2021

Marx 2021

Abasiyanik 2021

Alkhateeba 2021

Alkhateeba 2021

Alkhatee ba 2021

Bidka 2021

Stokes 2021

Fern?ndez-Gonz?lez 2021

Herrera 2021

Trobajo-Sanmart?n 2021

Random effects model

Heterogeneity: $t^{2}=87 \%, \tau^{2}=0.8238, p<0.01$

\section{Events Tota}

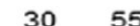

$\begin{array}{rr}33 & 39 \\ 30 & 3 \\ 91 & 10 \\ 53 & 5 \\ 12 & 1 \\ 34 & 5 \\ 75 & 8 \\ 41 & 5 \\ 16 & 19 \\ 15 & 1 \\ 67 & 7 \\ 4 & \\ 38 & 4 \\ 23 & 27 \\ 19 & 2 \\ 287 & 344\end{array}$

344

$39 \quad 43$

$55 \quad 70$

$16 \quad 17$

$104 \quad 122$

89

$20 \quad 23$

$47 \quad 49$

$33 \quad 34$

$32 \quad 34$

$30 \quad 33$

$28 \quad 30$

2830

$51 \quad 56$

$128 \quad 174$

$45 \quad 56$

6780

$60 \quad 76$

$44 \quad 47$

$46 \quad 54$

$16 \quad 16$

1215

412

$16 \quad 27$

$13 \quad 41$

$121 \quad 138$

3946

$139 \quad 173$

$168 \quad 324$

2919
Proportion

$95 \%-\mathrm{Cl}$

$0.545[0.406 ; 0.680]$

0.846 [0.695; 0.941$]$

0.857 [0.697; 0.952]

$0.867[0.786 ; 0.925]$

0.914 [0.810;0.971]

0.857 [0.572;0.982]

0.607 [0.468; 0.735 ]

$0.938[0.860 ; 0.979]$

0.788 [0.653; 0.889$]$

$0.842[0.604 ; 0.966]$

0.833 [0.586; 0.964]

0.944 [0.862; 0.984]

$0.800 \quad[0.284 ; 0.995]$

0.927 [0.801; 0.985]

0.852 [0.663; 0.958 ]

0.731 [0.522;0.884]

0.834 [0.791; 0.872 ]

$1.000 \quad[0.907 ; 1.000]$

$0.907[0.779 ; 0.974]$

0.786 [0.671; 0.875$]$

0.941 [0.713; 0.999]

0.852 [0.777; 0.910$]$

0.889 [0.518; 0.997]

0.870 [0.664: 0.972 ]

0.959 [0.860;0.995]

0.971 [0.847; 0.999]

0.941 [0.803; 0.993]

0.909 [0.757; 0.981$]$

0.933 [0.779; 0.992]

$0.933[0.779 ; 0.992]$

0.911 [0.804; 0.970$]$

0.736 [0.664; 0.799 ]

0.804 [0.676; 0.898]

0.838 [0.738;0.911]

0.789 [0.681; 0.875$]$

$0.936[0.825 ; 0.987]$

0.286 [0.037; 0.710$]$

0.852 [0.729; 0.934$]$

$1.000 \quad[0.794 ; 1.000]$

0.800 [0.519; 0.957$]$

0.333 [0.099; 0.651$]$

0.593 [0.388; 0.776 ]

0.317 [0.181; 0.481]

$0.877[0.810 ; 0.927]$

$0.848 \quad[0.711 ; 0.937]$

$0.803[0.736 ; 0.860]$

$0.519[0.463 ; 0.574]$

$0.848[0.805 ; 0.883]$ 
Appendix 5 - Forest plots of the specificity of the included studies.

\section{Study}

Akgun 2020

Williams 2020

Landry 2020

Griesemer 2020

Bhattacharya 2020

Byrne 2020

Caulley 2020

Hanson 2020

Moreno-Contreras 2020

Pasomsub 2020

Skolimowska 2020

Vaz 2020

Yokota, airport 2020

Yokota, contact 2020

Guclu 2020

Senok 2020

Altawalah 2020

Procop 2020

Kandel 2020

Braz-Silva 2020

Esther Babady 2020

Cheuk 2020

Iwasaki 2020

Kojima 2020

McCormick-Baw 2020

Miller 2020

Vogels 2020

Boerger 2021

Toppings 2021

Xun 2021

Masse 2021

Sasikala 2021

Mohd Thabit 2021

da Costa Fernandes 20201

da Costa Fernandes 2021

Marx 2021

Marx 2021

Marx 2021

Abasiyanik 2021

Alkhateeba 2021

Alkhatee ba 2021

Alkhateeba 2021

Bidka 2021

Stokes 2021

Fern?ndez-Gonz?lez 2021

Herrera 2021

Trobajo-Sanmart?n 2021

Random effects model

Heterogeneity: $I^{2}=89 \%, \tau^{2}=2.0146, p<0.01$

\section{Events Total}

$\begin{array}{rr}38 & 43 \\ 49 & 5 \\ 89 & 89 \\ 345 & 358 \\ 106 & 10 \\ 96 & 9 \\ 1869 & 1883\end{array}$

$268 \quad 274$

102130

$179 \quad 181$

112113

$82 \quad 84$

$1758 \quad 1758$

$114 \quad 120$

$33 \quad 37$

$366 \quad 375$

$177 \quad 178$

$383 \quad 386$

$131 \quad 131$

$\begin{array}{rr}69 & 70 \\ 70 & 107\end{array}$

$66 \quad 67$

$16 \quad 22$

$56 \quad 57$

$30 \quad 33$

$246 \quad 248$

$\begin{array}{lll}33 & 33 \\ 73 & 74 & -1 \\ 8 & 87\end{array}$

$85-87$

$26 \quad 26$

3640

142146

$16 \quad 16$

$147 \quad 150$

$292 \quad 295$

$436 \quad 442$

$\begin{array}{ll}69 & 76 \\ 18 & 18\end{array}$

3
20

$\begin{array}{rr}20 & 21 \\ 33 & 35\end{array}$

$171 \quad 175$

$1867 \quad 1877$

309312

11482
(1)

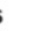

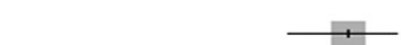

3

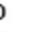

7

6

7

2

7

3

4

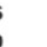

6

2

3

3

7

75

77

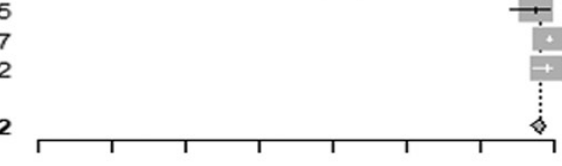

$\begin{array}{llllllll}0.3 & 0.4 & 0.5 & 0.6 & 0.7 & 0.8 & 0.9 & 1\end{array}$
Proportion

$95 \%-\mathrm{Cl}$

0.884 [0.749; 0.961]

0.980 [0.894; 0.999$]$

$1.000 \quad[0.959 ; 1.000]$

0.964 [0.939; 0.981]

$1.000 \quad[0.966 ; 1.000]$

$1.000 \quad[0.962 ; 1.000]$

0.993 [0.988; 0.996]

0.978 [0.953; 0.992]

0.785 [0.704; 0.852]

0.989 [0.961; 0.999]

$0.991 \quad[0.952 ; 1.000]$

0.976 [0.917; 0.997]

$1.000 \quad[0.998 ; 1.000]$

$0.950 \quad[0.894 ; 0.981]$

$0.892[0.746 ; 0.970]$

0.976 [0.955; 0.989$]$

0.967 [0.948; 0.980]

$0.994[0.969 ; 1.000]$

0.992 [0.977; 0.998]

$1.000 \quad[0.972 ; 1.000]$

0.986 [0.923; 1.000]

0.654 [0.556;0.744]

$0.985[0.920 ; 1.000]$

0.727 [0.498;0.893]

0.991 [0.949; 1.000]

0.982 [0.906; 1.000]

0.909 [0.757; 0.981]

0.992 [0.971; 0.999]

$1.000 \quad[0.894 ; 1.000]$

0.986 [0.927; 1.000]

0.977 [0.919; 0.997]

$1.000 \quad[0.868 ; 1.000]$

$0.900 \quad[0.763 ; 0.972]$

$0.973 \quad[0.931 ; 0.992]$

$1.000 \quad[0.794 ; 1.000]$

0.980 [0.943;0.996]

0.990 [0.971;0.998]

0.986 [0.971; 0.995]

$0.908 \quad[0.819 ; 0.962]$

1.000 [0.815; 1.000]

$1.000 \quad[0.292 ; 1.000]$

0.952 [0.762;0.999]

0.943 [0.808; 0.993]

0.714 [0.290; 0.963]

0.977 [0.943; 0.994]

0.995 [0.990; 0.997$]$

$0.990 \quad[0.972 ; 0.998]$

0.982 [0.971; 0.989$]$ 
Appendix 6 - Forest plots of the negative predictive value of the included studies.

Study

Akgun 2020

Williams 2020

Landry 2020

Griesemer 2020

Bhattacharya 2020

Byrne 2020

Caulley 2020

Hanson 2020

Moreno-Contreras 2020

Pasomsub 2020

Skolimowska 2020

Vaz 2020

Yokota, airport 2020

Yokota, contact 2020

Guclu 2020

Senok 2020

Altawalah 2020

Procop 2020

Kandel 2020

Braz-Silva 2020

Esther Babady 2020

Cheuk 2020

Iwasaki 2020

Kojima 2020

McCormick-Baw 2020

Miller 2020

Vogels 2020

Boerger 2021

Toppings 2021

Xun 2021

Masse 2021

Sasikala 2021

Mohd Thabit 2021

da Costa Fernandes 20201

da Costa Fernandes 2021

Marx 2021

Marx 2021

Marx 2021

Abasiyanik 2021

Alkhateeba 2021

Alkhateeba 2021

Alkhateeba 2021

Bidka 2021

Stokes 2021

Fern?ndez-Gonz?lez 2021

Herrera 2021

Trobajo-Sanmart?n 2021

Random effects model

Heterogeneity: $I^{2}=96 \%, \tau^{2}=3.0512, p<0.01$
Events Total

$\begin{array}{rr}38 & 63 \\ 49 & 55 \\ 89 & 94 \\ 345 & 359 \\ 106 & 111 \\ 96 & 98 \\ 1869 & 1891\end{array}$

$268 \quad 273$

$102 \quad 113$

$179 \quad 182$

112115

8286

$\begin{array}{rr}1758 & 1759 \\ 114 & 117\end{array}$

$33 \quad 37$

$366 \quad 373$

$529 \quad 586$

$177 \quad 177$

$383 \quad 387$

$131 \quad 146$

6970

$\begin{array}{ll}70 & 88 \\ 66 & 67\end{array}$

$16 \quad 19$

105107

$56 \quad 57$

$\begin{array}{rr}30 & 32 \\ 246 & 249\end{array}$

$33 \quad 35$

$73 \quad 75$

8590

$26 \quad 72$

$\begin{array}{rr}36 & 47 \\ 142 & 155\end{array}$

$16 \quad 32$

$147 \quad 150$

$292 \quad 297$

$436 \quad 444$

6969

$3 \quad 11$

20

33

171

$1867 \quad 1901$

$309 \quad 465$

11867

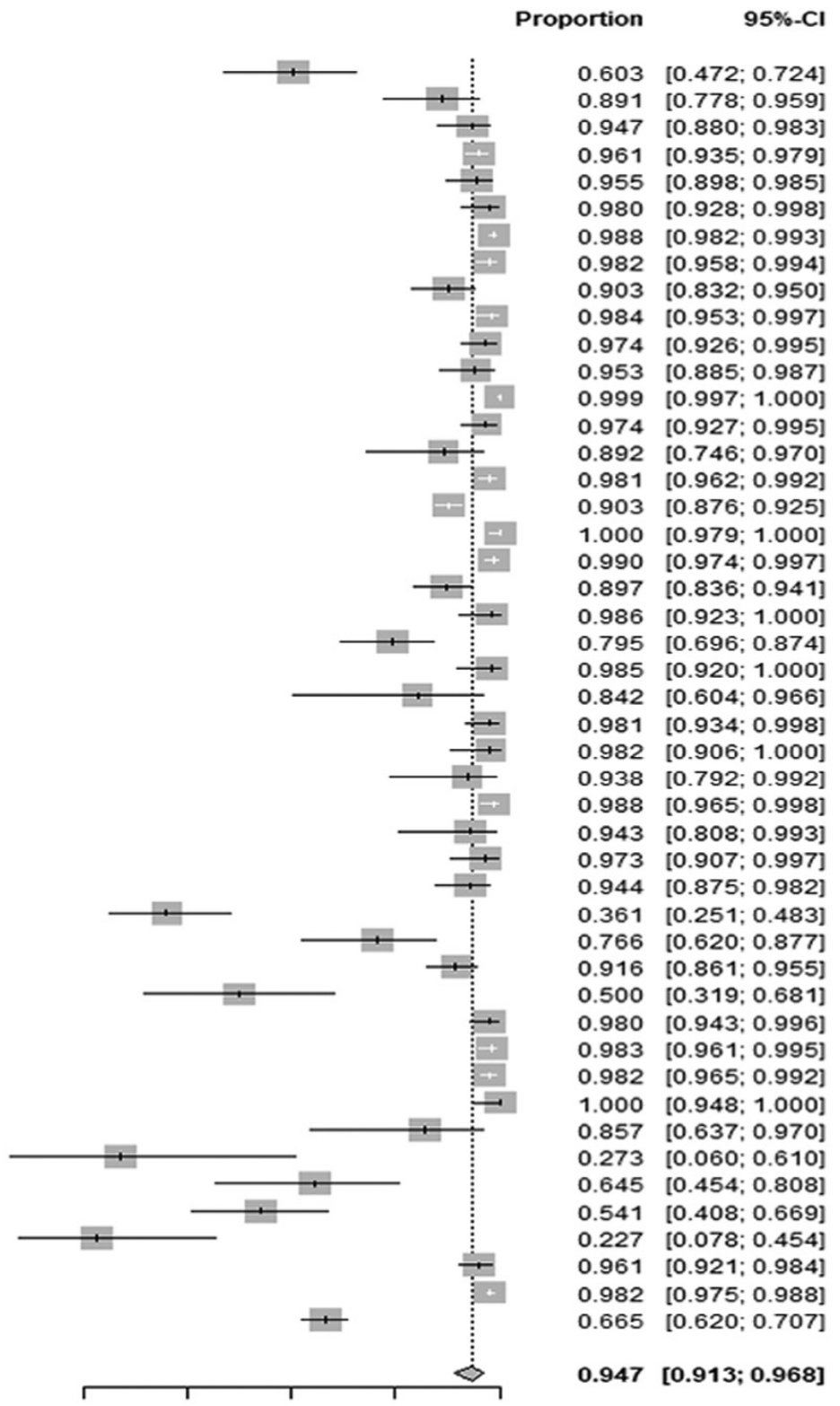

$0.603 \quad[0.472 ; 0.724]$

0.961 [0.935; 0.979$]$

[0.898; 0.985]

0.988 [0.982; 0.993]

0.982 [0.958; 0.994$]$

0.903 [0.832; 0.950 ]

[0.953; 0.997]

0.953 [0.885; 0.987]

0.999 [0.997; 1.000]

.9701

0.903 [0.8

$1.000 \quad[0.979 ; 1.000]$

[0.974; 0.997]

[0.836; 0.941]

0.985 [0.920; 1.000$]$

0.842 [0.604; 0.966 ]

0.981 [0.934; 0.998 ]

[0.906; 1.000]

0.988 [0.965; 0.998]

0.943 [0.808; 0.993]

0.973 [0.907; 0.997$]$

0.944 [0.875; 0.982]

0.361 [0.251; 0.483]

[0.620:0.877]

0.916 [0.861; 0.955]

0.500 [0.319; 0.681$]$

0.980 [0.943; 0.996]

0.983 [0.961; 0.995]

0.982 [0.965; 0.992]

1.000 [0.948; 1.000$]$

0.857 [0.637; 0.970$]$

0.273 [0.060;0.610]

0.645 [0.454; 0.808$]$

$0.541 \quad[0.408 ; 0.669]$

0.227 [0.078; 0.454$]$

0.961 [0.921; 0.984]

0.982 [0.975; 0.988]

$0.947[0.913 ; 0.968]$ 
Appendix 7 - Forest plots of the positive predictive value of the included studies.

Study

Akgun 2020

Williams 2020

Landry 2020

Griesemer 2020

Bhattacharya 2020

Byrne 2020

Caulley 2020

Hanson 2020

Moreno-Contreras 2020

Pasomsub 2020

Skolimowska 2020

Vaz 2020

Yokota, airport 2020

Yokota, contact 2020

Guclu 2020

Senok 2020

Altawalah 2020

Procop 2020

Kandel 2020

Braz-Silva 2020

Esther Babady 2020

Cheuk 2020

Iwasaki 2020

Kojima 2020

McCormick-Baw 2020

Miller 2020

Vogels 2020

Boerger 2021

Toppings 2021

Xun 2021

Masse 2021

Sasikala 2021

Mohd Thabit 2021

da Costa Fernandes 20201

da Costa Fernandes 2021

Marx 2021

Marx 2021

Marx 2021

Abasiyanik 2021

Alkhateeba 2021

Alkhatee ba 2021

Alkhateeba 2021

Bidka 2021

Stokes 2021

Fern?ndez-Gonz?lez 2021

Herrera 2021

Trobajo-Sanmart?n 2021

Random effects model

Heterogeneity: $I^{2}=83 \%, \tau^{2}=1.3518, p<0.01$

\section{Events Total}

$30 \quad 35$

$\begin{array}{ll}33 & 34 \\ 30 & 30\end{array}$

$91 \quad 104$

5353

1212

$34 \quad 48$

$75 \quad 81$

$41 \quad 69$

1618

1516

$67 \quad 69$

$\begin{array}{rr}48 & 44\end{array}$

$23 \quad 27$

$19 \quad 28$

$287 \quad 305$

$38 \quad 39$

$39 \quad 42$

$55 \quad 55$

$16 \quad 17$

$\begin{array}{rr}104 & 141 \\ 8 & 9\end{array}$

$20 \quad 26$

$47 \quad 48$

$33 \quad 34$

$32 \quad 35$

$30 \quad 32$

$28 \quad 28$

$28 \quad 29$

$51 \quad 53$

$128 \quad 128$

$45 \quad 49$

$67 \quad 71$

6060

$44 \quad 47$

$\begin{array}{rr}2 & 5 \\ 46 & 52\end{array}$

$16 \quad 23$

$12 \quad 12$

$\begin{array}{rr}4 & 4 \\ 16 & 17\end{array}$

$13 \quad 15$

$121 \quad 123$

3943

139149

$168 \quad 171$

2534

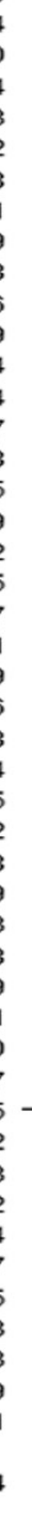

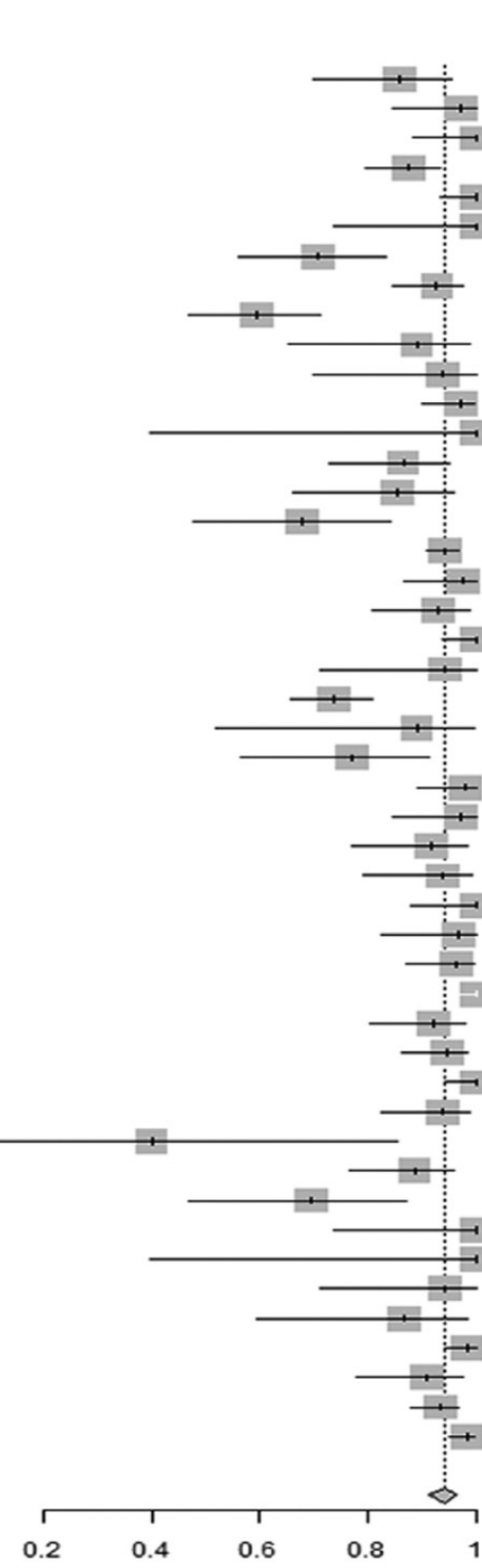

Proportion

$95 \%-\mathrm{Cl}$

0.857 [0.697; 0.952]

0.971 [0.847; 0.999 ]

$1.000 \quad[0.884 ; 1.000]$

0.875 [0.796; 0.932$]$

$1.000 \quad[0.933 ; 1.000]$

$1.000[0.735 ; 1.000]$

0.708 [0.559; 0.830$]$

0.926 [0.846; 0.972]

0.594 [0.469; 0.711]

0.889 [0.653;0.986]

0.938 [0.698; 0.998]

0.971 [0.899; 0.996]

1.000 [0.398; 1.000]

0.864 [0.726: 0.948]

0.852 [0.663; 0.958 ]

0.679 [0.476; 0.841$]$

0.941 [0.908; 0.965]

0.974 [0.865;0.999]

0.929 [0.805; 0.985]

$1.000[0.935 ; 1.000]$

0.941 [0.713; 0.999]

0.738 [0.657; 0.808 ]

0.889 [0.518; 0.997$]$

$0.769[0.564 ; 0.910]$

0.979 [0.889;0.999]

0.971 [0.847; 0.999]

0.914 [0.769; 0.982$]$

0.938 [0.792; 0.992]

1.000 [0.877; 1.000$]$

0.966 [0.822; 0.999]

0.962 [0.870; 0.995 ]

$1.000 \quad[0.972 ; 1.000]$

$0.918[0.804 ; 0.977]$

0.944 [0.862;0.984]

$1.000[0.940 ; 1.000]$

0.936 [0.825; 0.987 ]

0.400 [0.053; 0.853]

0.885 [0.766; 0.956 ]

0.696 [0.471; 0.868]

$1.000[0.735 ; 1.000]$

$1.000 \quad[0.398 ; 1.000]$

0.941 [0.713; 0.999]

0.867 [0.595; 0.983]

0.984 [0.942; 0.998 ]

0.907 [0.779; 0.974$]$

0.933 [0.880; 0.967 ]

0.982 [0.950; 0.996]

$0.940[0.912 ; 0.960]$ 
Appendix 8 - Forest plots of A) the sensitivity, B) the specificity, C) the negative predictive value, and D) the positive predictive value regarding the effect of geographic differences on self-collected saliva for COVID-19.

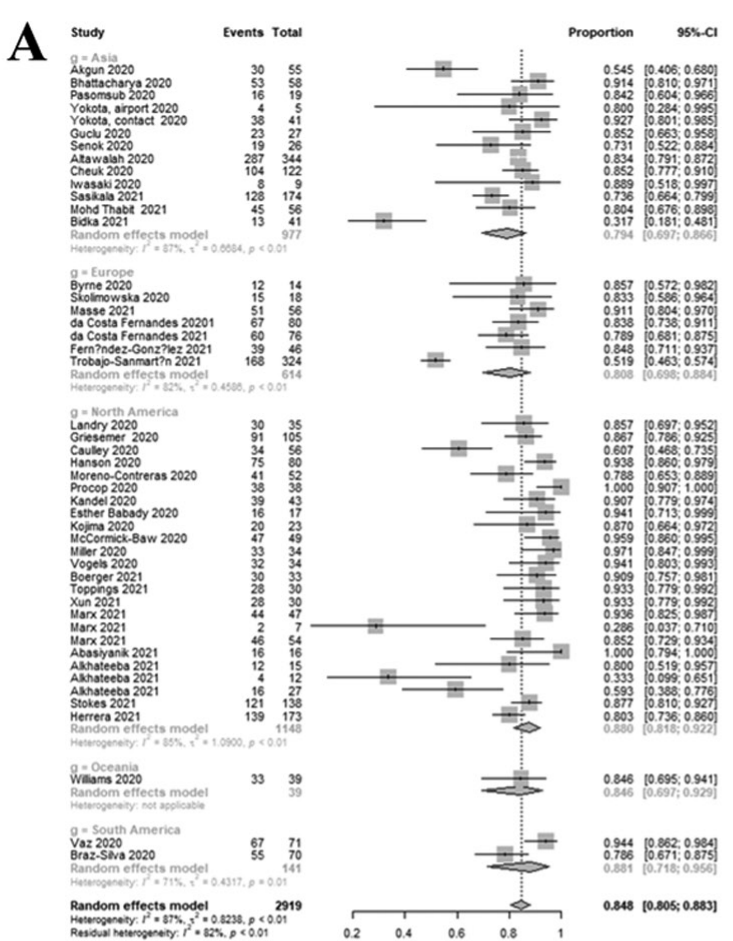

B

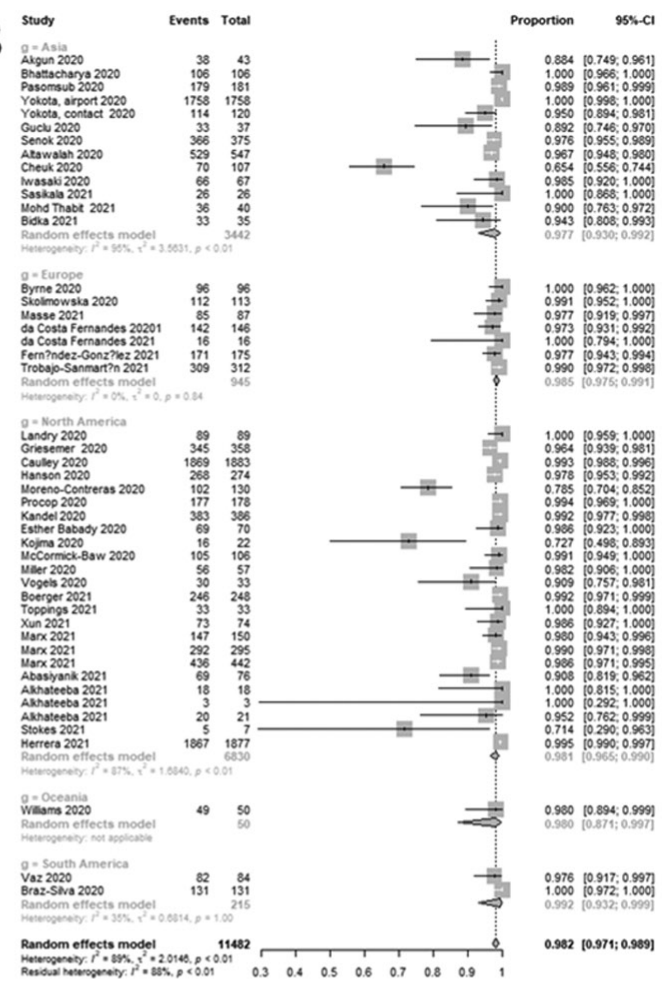

C
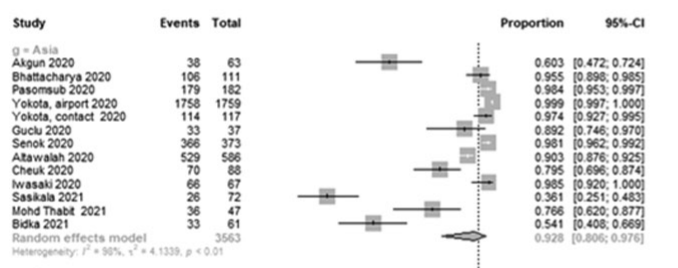

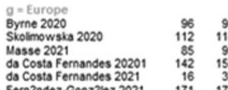

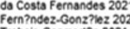
Trobajo-Sanmartin 2021

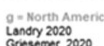
Gresemerer
Couluey 2020
Hanson 2020

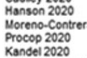

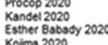
Koint 2020
vecormick-Baw 2020 Wher 20200 Boerger 2021 Tun 2021
Marx 2021
$\operatorname{Mox} 2022$

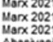

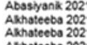

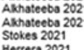
Hetrets 2021
Randor effects model
Rnnom

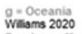

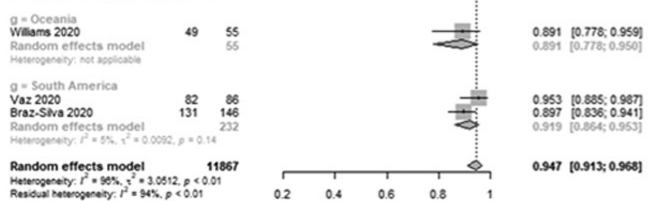

D

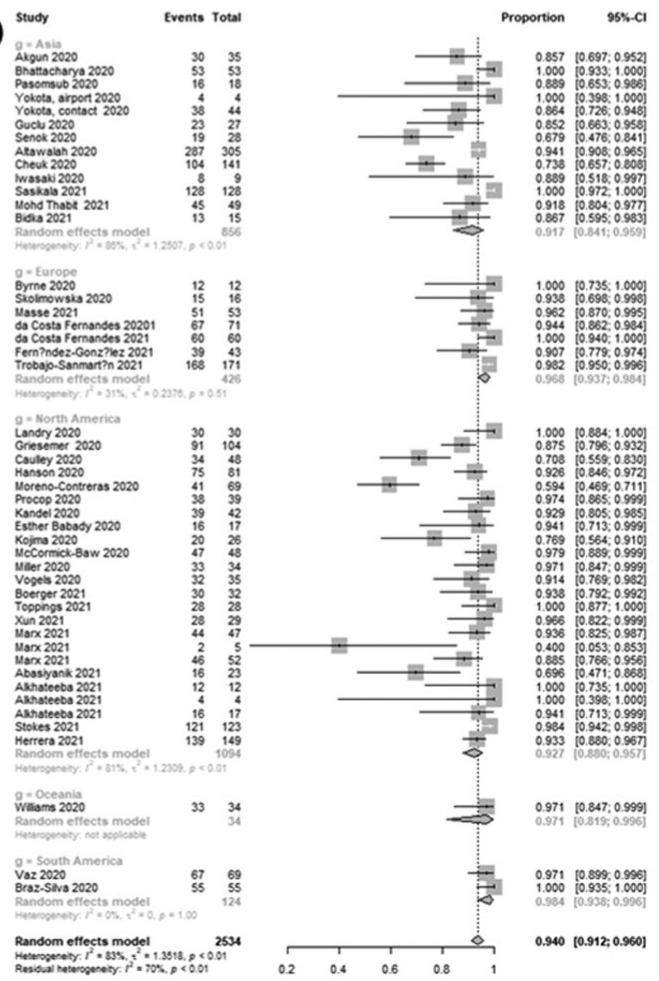


Appendix 9 - Forest plots of A) the sensitivity, B) the specificity, C) the negative predictive value, and D) the positive predictive value regarding the effect of saliva collection method on self-collected saliva for COVID-19.

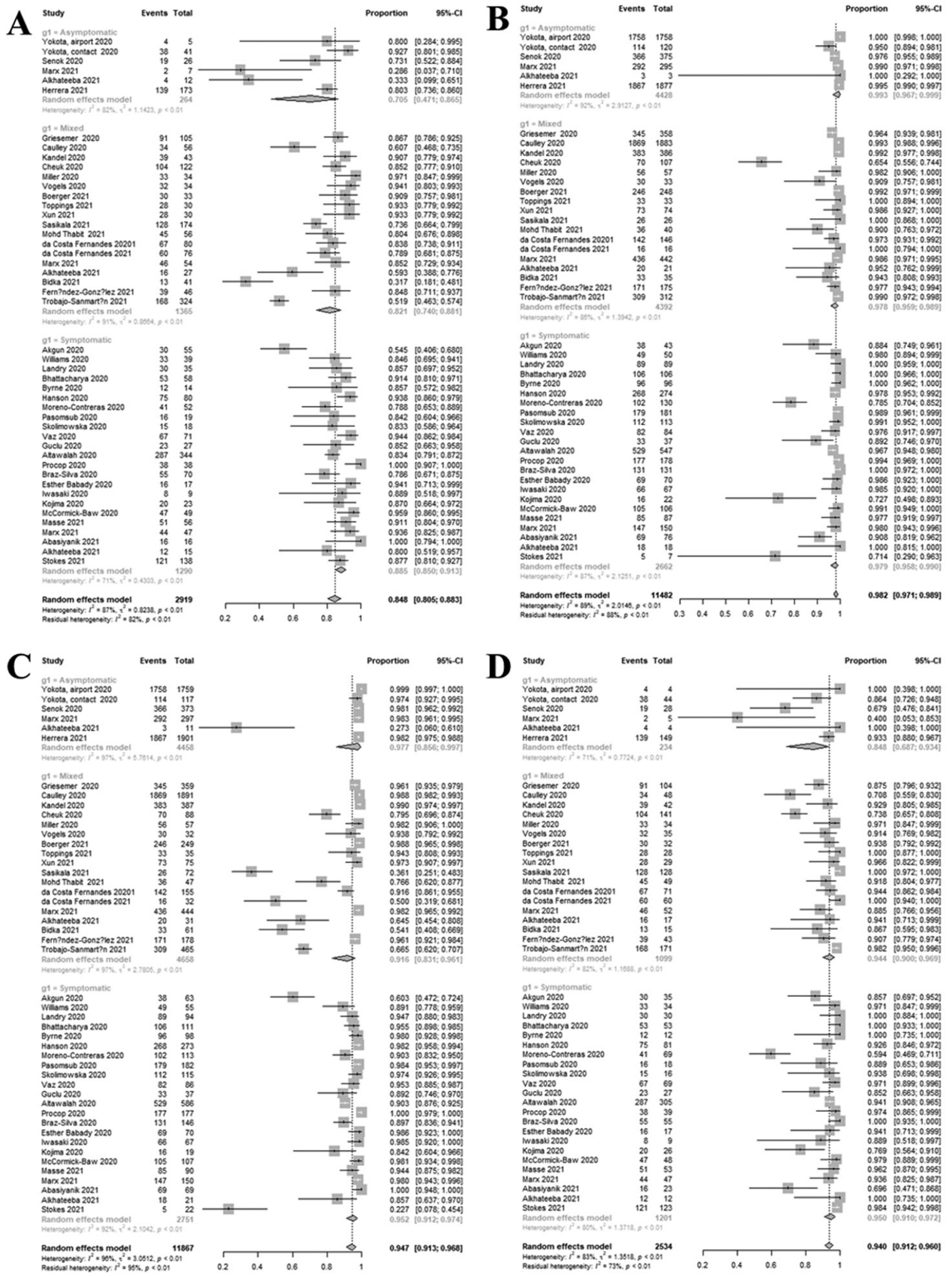


Appendix 10 - Forest plots of A) the sensitivity, B) the specificity, C) the negative predictive value, and D) the positive predictive value regarding the effect of presence or absence of symptoms on the diagnostic odds ratios on self-collected saliva for COVID- 19 .

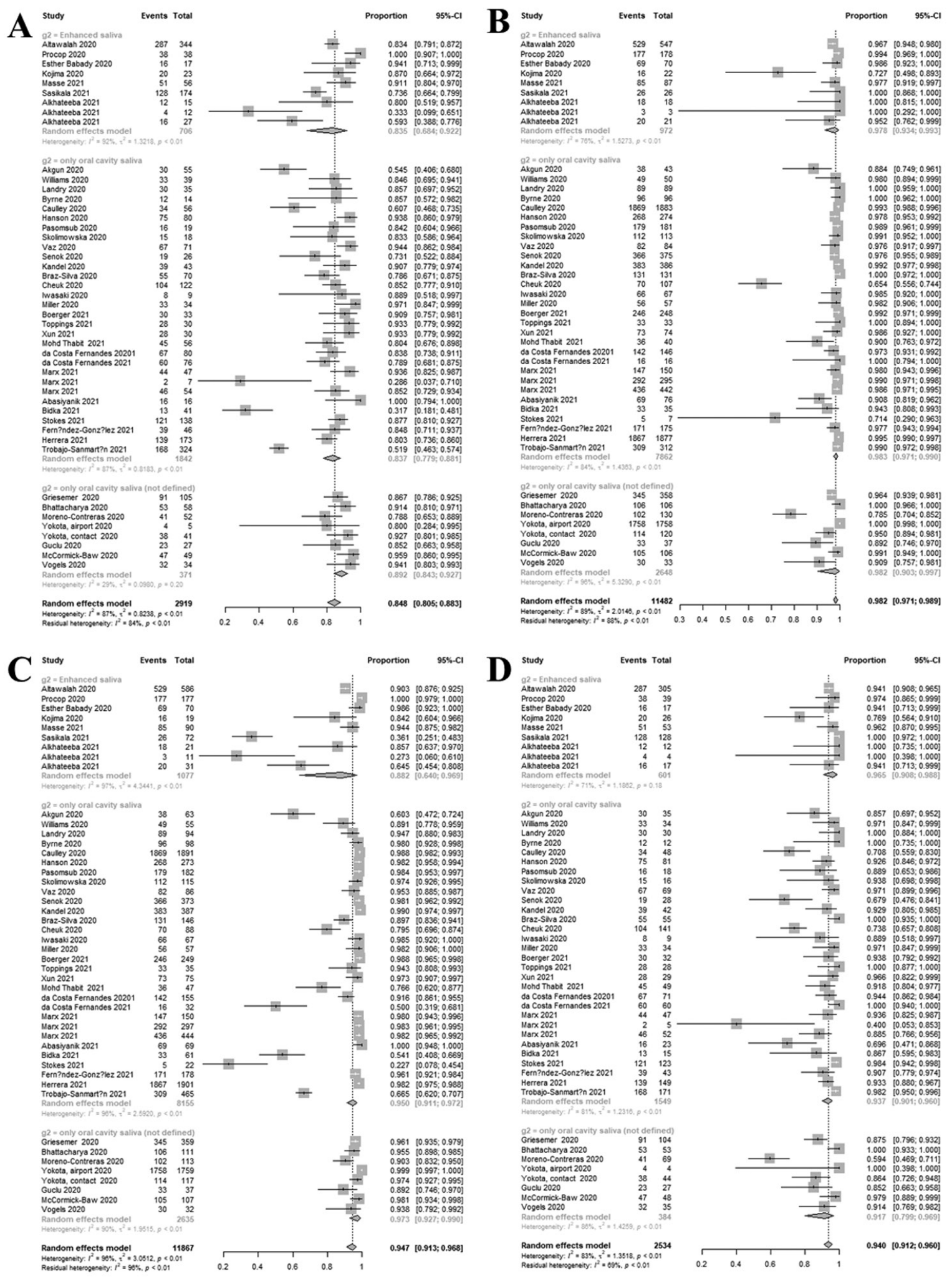


Appendix 11 - The effect of geographic differences on the diagnostic odds ratios of self-collected saliva for COVID-19.

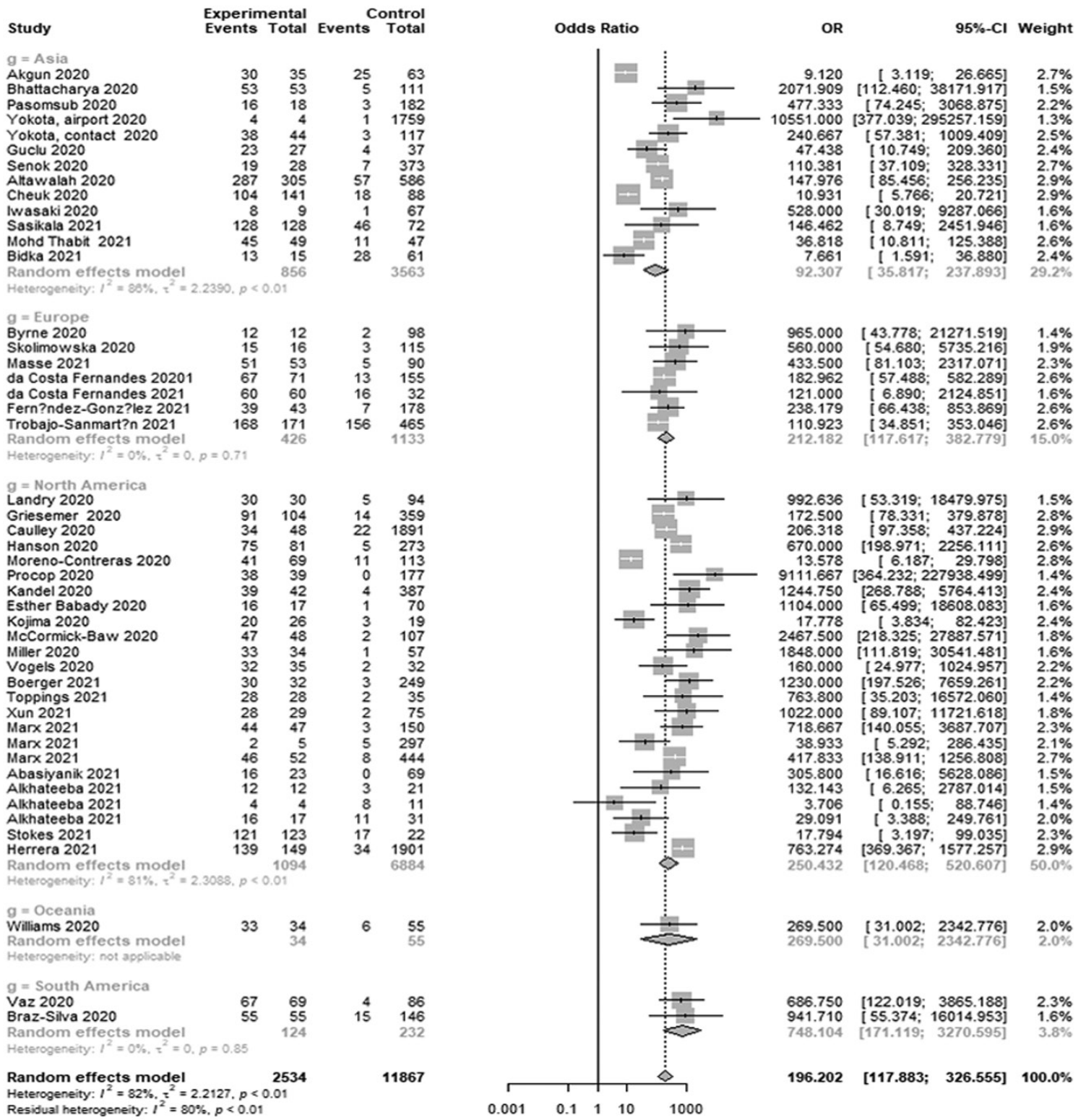


Saliva tests for COVID-19 ... Kim et al

Appendix 12 - The effect of saliva collection method on the diagnostic odds ratios of self-collected saliva for COVID-19.

Study

Experimental Control
Events Total Events Total

g1 = Asymptomatic

Yokota, airport 2020

Yokota, contact 2020

Senok 2020

Marx 2021

Alkhateeba 2021

Herrera 2021

Random effects model

$\begin{array}{llll}4 & 4 & 1 & 1759\end{array}$

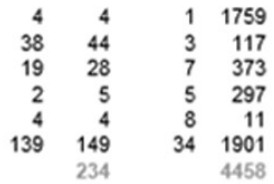

Heterogeneity: $l^{2}=80 \%, \tau^{2}=2.2092, p<0.01$

g1 $=$ Mixed

Griesemer 2020

Caulley 2020

Kandel 2020

Cheuk 2020

Miler 2020

Vogels 2020

Boerger 2021

Toppings 2021

Xun 2021

Sasikala 2021

Mohd Thabit 2021

da Costa Fernandes 20201

da Costa Fernandes 2021

Marx 2021

Alkhateeba 2021

Bidka 2021

Fern?ndez-Gonz?lez 2021

Trobajo-Sanmart?n 2021

Random effects model

$\begin{array}{rrrr}91 & 104 & 14 & 359 \\ 34 & 48 & 22 & 1891 \\ 39 & 42 & 4 & 387 \\ 104 & 141 & 18 & 88 \\ 33 & 34 & 1 & 57 \\ 32 & 35 & 2 & 32 \\ 30 & 32 & 3 & 249 \\ 28 & 28 & 2 & 35 \\ 28 & 29 & 2 & 75 \\ 128 & 128 & 46 & 72 \\ 45 & 49 & 11 & 47 \\ 67 & 71 & 13 & 155 \\ 60 & 60 & 16 & 32 \\ 46 & 52 & 8 & 444 \\ 16 & 17 & 11 & 31 \\ 13 & 15 & 28 & 61 \\ 39 & 43 & 7 & 178 \\ 168 & 171 & 156 & 465 \\ & 1099 & & 4658\end{array}$

g1 = Symptomatic

Akgun 2020

Willams 2020

Landry 2020

Bhattacharya 2020

Byrne 2020

Hanson 2020

Moreno-Contreras 2020

Pasomsub 2020

Skolimowska 2020

Vaz 2020

Guclu 2020

Altawalah 2020

Procop 2020

Braz-Silva 2020

Esther Babady 2020

Iwasaki 2020

Koïma 2020

McCormick-8aw 2020

Masse 2021

Marx 2021

Abasiyanik 2021

Alkhateeba 2021

Stokes 2021

Random effects model

Heterogeneity; $l^{2}=81 \%, z^{2}=2.5960, p<0.01$

Random effects model

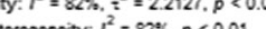

Odds Ratio

OR

95\%-Cl Weight

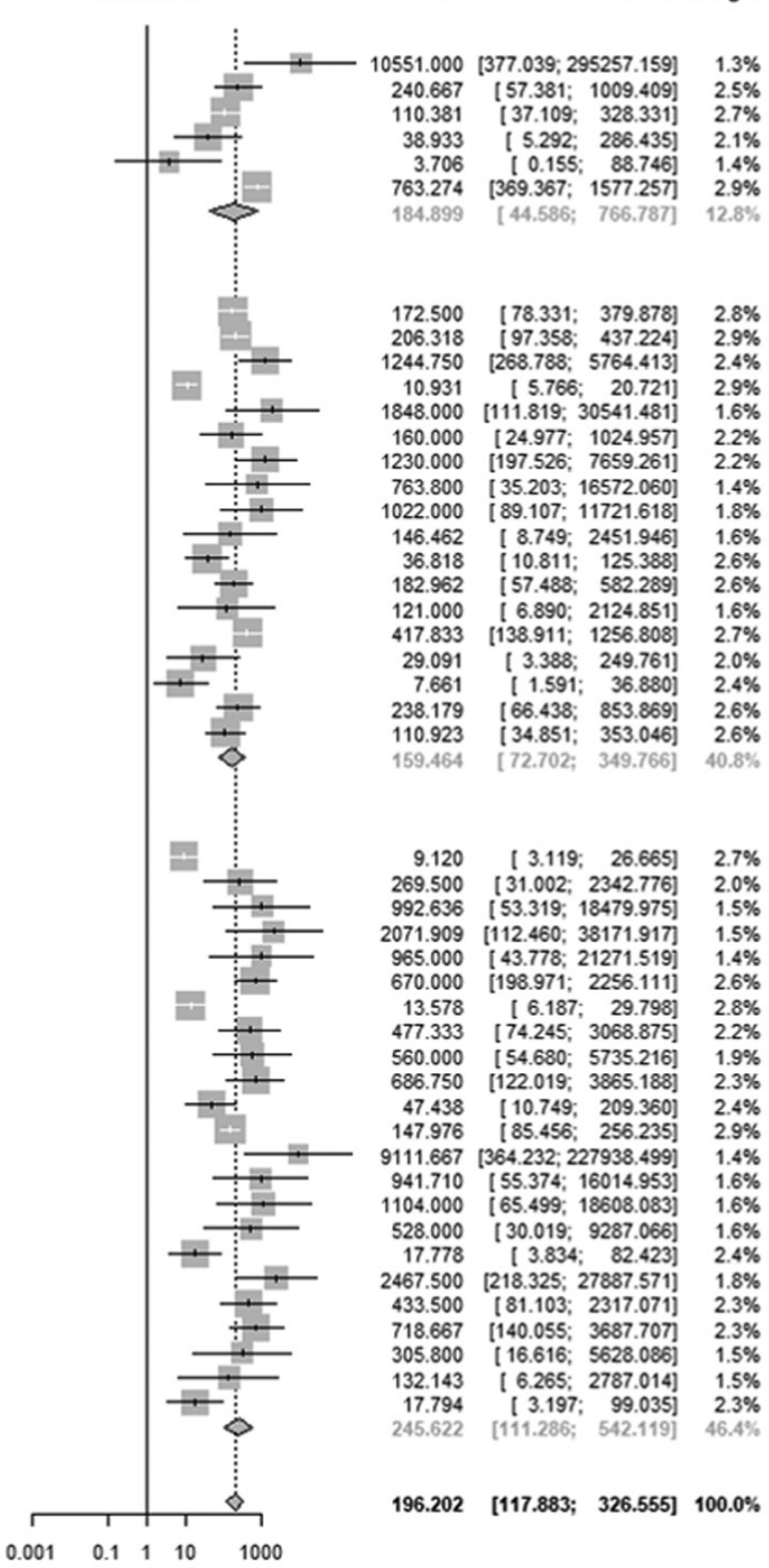


Saliva tests for COVID-19 ... Kim et al

Appendix 13 - The effect of presence or absence of symptoms on the diagnostic odds ratios of self-collected saliva for COVID-19.

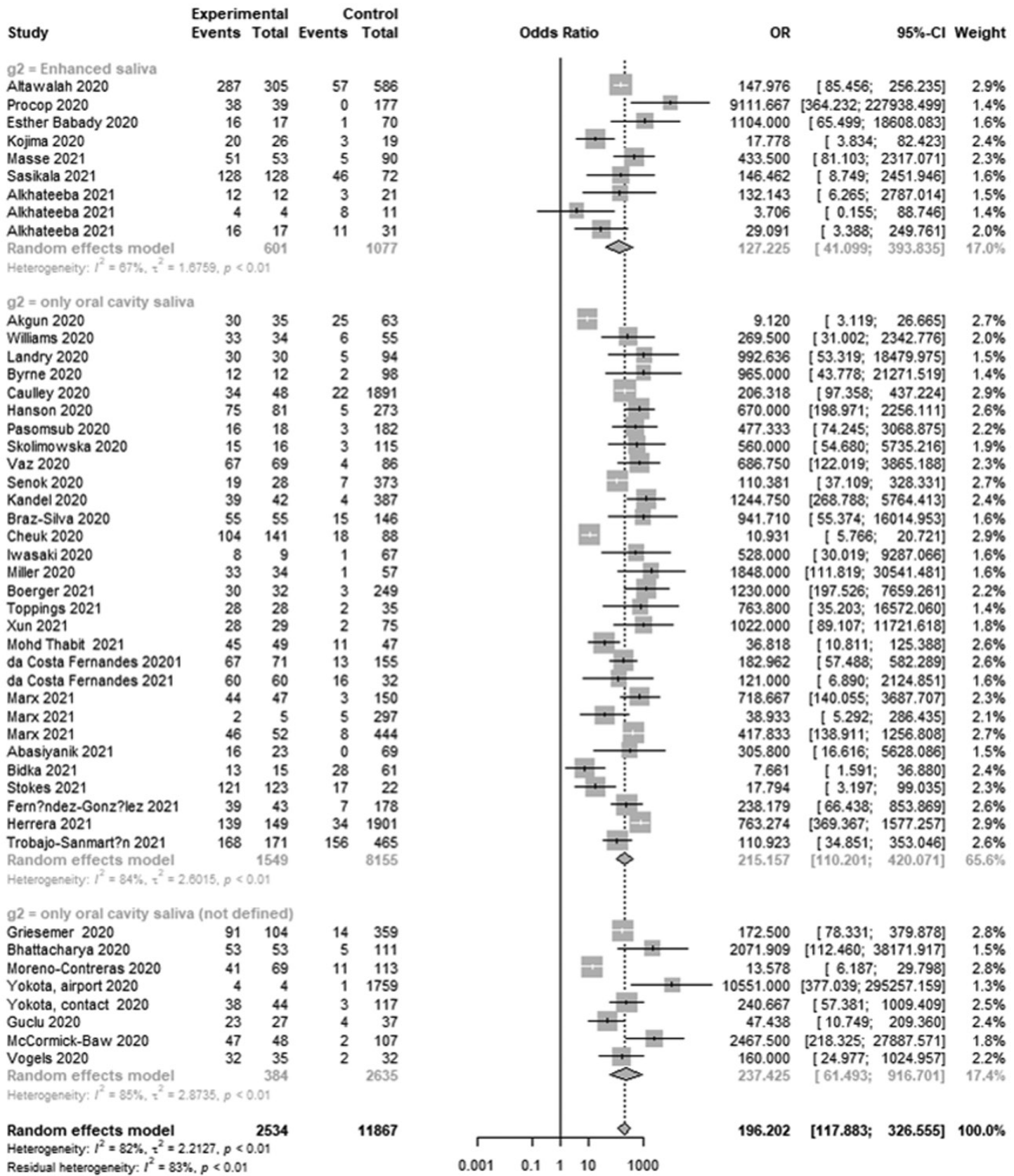

